UNIVERSIDADE DE SÃO PAULO

HOSPITAL DE REABILITAÇÃO DE ANOMALIAS CRANIOFACIAIS

\title{
SÍNDROME KABUKI: DIAGNÓSTICO FONOAUDIOLÓGICO
}

ALINE SILVA LARA DE ALVARENGA

Tese apresentada ao Hospital de Reabilitação de Anomalias Craniofaciais da Universidade de São Paulo, para obtenção do título de DOUTOR em Ciências da Reabilitação.

Área de Concentração: Distúrbios da Comunicação 
UNIVERSIDADE DE SÃO PAULO

HOSPITAL DE REABILITAÇÃO DE ANOMALIAS CRANIOFACIAIS

\title{
SÍNDROME KABUKI: DIAGNÓSTICO FONOAUDIOLÓGICO
}

\author{
ALINE SILVA LARA DE ALVARENGA \\ Prof. Dr. Neivo Luiz Zorzetto
}

\begin{abstract}
Tese apresentada ao Hospital de Reabilitação de Anomalias Craniofaciais da Universidade de São Paulo, para obtenção do título de DOUTOR em Ciências da Reabilitação.

Área de Concentração: Distúrbios da Comunicação
\end{abstract}




\section{UNIVERSIDADE DE SÃO PAULO HOSPITAL DE REABILITAÇÃO DE ANOMALIAS CRANIOFACIAIS}

Rua Silvio Marchione, 3-20

Caixa postal: 1501

17012-900 - Bauru/SP - Brasil

(14) $3235-8000$

Prof. Dr. Adolpho José Melfi - Reitor da USP

Prof. Dr. José Alberto de Souza Freitas - Superintendente HRAC/USP

Autorizo, exclusivamente, para fins acadêmicos, a reprodução total ou parcial deste trabalho

Aline Silva Lara de Alvarenga

Bauru, 11 de agosto de 2006

\begin{tabular}{|l}
\hline A86s \\
Alvarenga, Aline Silva Lara de \\
Síndrome Kabuki: Diagnóstico Fonoaudiológico / Aline \\
Silva Lara de Alvarenga. Bauru, 2006. \\
$84 \mathrm{f.} ; 30 \mathrm{~cm}$ \\
Tese de doutorado - Distúrbios da Comunicação - \\
HRAC/USP \\
Orientador: Neivo Luiz Zorzetto \\
Descritores: 1. Síndrome Kabuki; 2. Genética; 3. \\
Linguagem; 4. Fala.
\end{tabular}




\section{FOLHA DE APROVAÇÃO}

Tese apresentada e defendida por

e aprovada pela comissão julgadora em

\section{Prof.(a) Dr(a)}

Instituição

Prof.(a) $\operatorname{Dr}($ a)

Instituição

Prof.(a) Dr(a)

Instituição

Prof.(a) Dr(a)

Instituição

Prof.(a) Dr(a)

Instituição (Orientador)

Prof.(a) Dr(a)

Presidente da Comissão de Pós Graduação do HRAC/USP

Data de depósito da tese junto à SPG 11/08/2006. 


\section{ALINE SILVA LARA DE ALVARENGA}

05 de agosto de 1971

Bauru/SP

$1991-1994$

$1996-1999$

1999

$1998-2001$

$2000-2004$

$2005-$

$2005-$

2006-

Associações

\author{
Nascimento
}

- Graduação. Curso de Fonoaudiologia Faculdade de Odontologia de Bauru da Universidade de São Paulo/USP

- Mestrado em Educação Especial. Universidade Federal de São Carlos UFSCar

- Especialização em Linguagem. Conselho Federal de Fonoaudiologia

Professora auxiliar na área de Linguagem e Fluência da Universidade Paulista em Ribeirão Preto

Professora convidada na área de Linguagem e Fluência do Curso de Fonoaudiologia da Faculdade de Odontologia de Bauru da Universidade de São Paulo

Professora auxiliar do Curso de Fonoaudiologia da Universidade do Estado da Bahia em Salvador/BA

Professora assistente do Curso de Fonoaudiologia da União Metropolitana de Educação e Cultura em Lauro de Freitas/BA

Professora do Curso de Especialização em Fonoaudiologia Neonatal da União Metropolitana de Educação e Cultura em Lauro de Freitas/BA

Sociedade Brasileira de Fonoaudiologia 
Porque você não soube das escolhas mas viveu cada uma delas; Porque foi capaz de compreender minhas ausências e "nãos" muito além do que eu pude imaginar que seria capaz... E eu que pensei que você seria muito pequeno para isso...

Porque no seu sorriso encontrei a força e a razão para continuar;

Para Rubens,

Porque suportou a ausência e se fez presente;

Porque tornou suas as minhas escolhas. Valeu a pena toda distância, todo sofrimento, todas as renúncias. Valeu a pena esperar! Hoje colhemos, juntos, os frutos do nosso empenho! A vitória é muito mais sua do que minha!!!

Para Nardi e Marlene, Porque sempre me conduziram sem empurrar ou puxar, porque me permitiram experimentar sempre, e com liberdade me mostraram que o fundamental na vida é o amor! O exemplo de vida de vocês é o meu rumo! 


\section{AGRADEÇO ESPECIALMENTE}

A Deus, que por Sua infinita misericórdia e amor permitiu-me traçar um caminho de crescimento, de aprendizado, de convivência com pessoas queridas, de vitórias sobre os desafios, de superação das inseguranças, de valorização do ser humano.

Aos meus pais, Nardi e Marlene, por serem tão presentes e tão incríveis. Por serem serenos e acolhedores. Obrigada pelo incentivo e dedicação desde as primeiras letras! Aproveito para manifestar além do meu amor, o imenso orgulho e admiração que tenho de vocês.

À minha irmã e amiga Aliane, que foi além de colaboradora na filmagem dos participantes. Obrigada por se envolver e trabalhar comigo! Sem sua ajuda não seria possível!

Ao meu irmão André, pelo carinho e interesse sempre. Minha admiração e amor por você e a família linda que tem é muito maior do que o que sei expressar.

A minha amiga Regina, pela amizade, pela torcida, por me ajudar também na reta final! Mesmo na distância sua presença na minha vida é carinhosa e alegre.

A minha desde sempre amiga Marília, que sempre foi ouvido, olho, ombro e colo nos momentos de angústias e frustrações e sempre foi ouvido, olho, ombro e colo nos momentos de certezas e alegrias. Obrigada por trazer a luz da emoção para um coração cheio de razão! 


\section{AGRADEÇO TAMBÉM}

Ao meu orientador Prof. Dr. Neivo Luiz Zorzetto, pela oportunidade de aprendizado, pela dedicação e confiança;

À minha co-orientadora Profa. Dra. Célia Maria Giacheti, pela confiança depositada em mim, pelo incentivo, pela compreensão e pela oportunidade de aprendizado profissional;

À Prof. Dra. Inge Elly Kienlly Trindade, coordenadora do Programa de Pós Graduação deste Hospital, pela dedicação e incentivo;

Aos professores do Programa de Pós-Graduação, pela dedicação e disponibilidade;

À Andréia, da Secretaria da Pós-Graduação, pela dedicação, pelo carinho, pela amizade. Obrigada pela disponibilidade e atenção sempre;

Aos professores Dra. Luciana Paula Maximino De Vitto, Dra. Célia Maria Giacheti e Dr. Adriano Yacubian Fernandes pela atenção cuidadosa, observações e sugestões oferecidas no exame de qualificação;

Aos colegas de turma, Marileda, Ester, Rosana, Nancy, Carlos Eduardo, Regina, e Eloísa, a convivência com vocês foi maravilhosa e muito gratificante;

Dr. Richieri, Cida, Elisandra, Tatiana, Aleide, e a todos do setor que me ajudaram e participaram deste trabalho. Obrigada pelo envolvimento e apoio, sem vocês não seria possível;

À Carol e Suka que estiveram ao meu lado e participaram das buscas e angústias da reta final, obrigada por estarem por perto e dividirem o peso. A amizade de vocês é preciosa para mim! 
Aos funcionários da Unidade de Ensino e Pesquisa, pela atenção e auxílio na parte bibliográfica;

Aos funcionários do CPD, pelo auxílio prestado na identificação e localização dos pacientes;

Aos pacientes que participaram deste estudo, alcancei muito mais do que determinei como objetivo deste trabalho. Aprendi mais sobre a vida e a superação com o exemplo de vocês e de suas famílias. 


\section{SUMÁRIO}

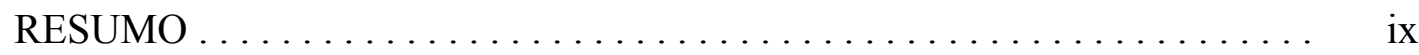

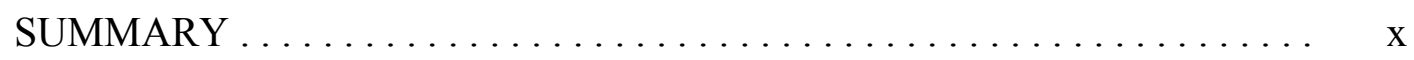

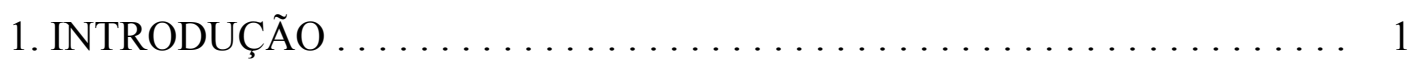

2. REVISÃO DE LITERATURA $\ldots \ldots \ldots \ldots \ldots \ldots \ldots \ldots \ldots \ldots$

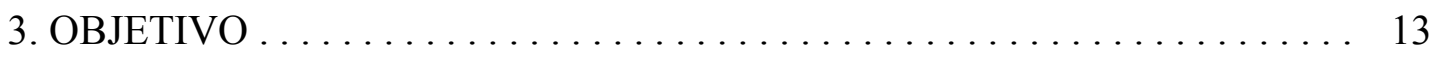

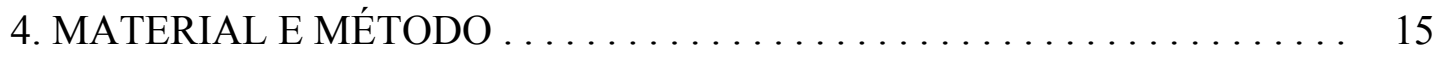

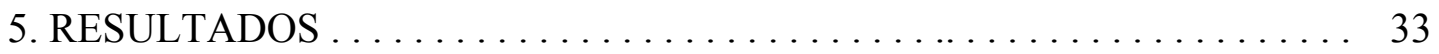

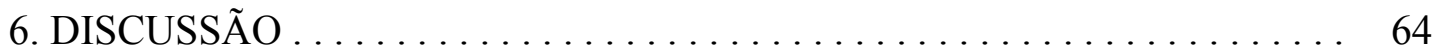

7. CONCLUSÕES ............................... 74

8. REFERÊNCIAS BIBLIOGRÁFICAS . . . . . . . . . . . . . . 77

ANEXOS 


\section{RESUMO}

ALVARENGA, A. S. L. Síndrome Kabuki: Diagnóstico Fonoaudiológico [tese]. Bauru: Hospital de Reabilitação de Anomalias Cranifaciais, Universidade de São Paulo; 2006.

Objetivo: O objetivo deste estudo, portanto, é caracterizar a linguagem oral de indivíduos portadores da Síndrome Kabuki (SK).

Existem ainda poucos estudos sobre a SK e as habilidades lingüísticas dos indivíduos por ela acometidos.

Material e Método: participaram deste estudo 6 sujeitos com SK compondo o grupo investigado (GI) e 12 sujeitos compondo o grupo controle (GC). Todos os sujeitos foram submetidos à anamnese fonoaudiológica, avaliação audiológica, avaliação clínica fonoaudiológica e avaliação fonoaudiológica complementar.

Resultados: os achados fonoaudiológicos evidenciaram que $66 \%$ dos sujeitos com SK apresentavam perda auditiva. As habilidades lingüísticas dos sujeitos com SK apresentaram-se comprometidas quando comparadas com o GC pareados por sexo e idade mental. Todos os sujeitos com SK apresentaram comprometimento da funcionalidade da comunicação. Os dados da avaliação clínica, comparados aos dados do Teste Illinois de Habilidades Psicolingüísticas (ITPA), evidenciaram que o indivíduo com menor alteração da linguagem apresentou comprometimento na maioria dos subtestes do ITPA, caracterizando alteração nas habilidades perceptivas auditivas e visuais.

Conclusões: Os sujeitos com SK apresentaram relevante comprometimento da funcionalidade da comunicação quando comparados aos indivíduos do GC, sem a referida síndrome. O comprometimento cognitivo pode levar o indivíduo a esta condição e a deficiência auditiva, quando presente, pode agravar o quadro. As alterações da fala relacionadas à produção dos sons pode estar diretamente relacionada ao déficit cognitivo encontrado nos sujeitos deste estudo e ao comprometimento perceptual auditivo encontrado na população;

Palavras-chave: Síndrome Kabuki, Genética, Linguagem, Fala, Aprendizagem. 


\section{SUMMARY}

ALVARENGA, ASL. Kabuki Symdrome: speech and language Diagnosis [thesis]. Bauru: Cranianfacial Anomaly Reabilitation Hospital, São Paulo University; 2006.

Aim: the objective of this study is to characterize the oral language of Kabuki Syndrome (KS) affected population.

There are few studies about KS and the linguistic abilities of population affected population.

Material and Method: $6 \mathrm{KS}$ holders took part in this study compounding the investigated group (IG) and 12 people compounding the control group (CG). All of them were submitted to anamnesis, audiologic assessment, clinical communication evaluation and communication complementary evaluation.

Results: The findings showed that $66 \%$ of KS holders had hearing impairment. The linguistic abilities of KS holders were bind when compared to the CG separated by sex and mental age. All of the KS holders had communication functionality disability. The clinical evaluation data, compared with data from the Illinois Test of Psycholinguistic Ability (ITPA), showed that the person with less speech alteration showed less alteration results in most of ITPA subtests when compared with others holders of the same group.

Conclusions: The KS affected population showed relevant disabilities in functionality communication when compared with the $\mathrm{CG}$, people not affected by the syndrome. The cognitive disabilities can lead the person to this condition and the hearing impairment, when present, may make the situation worse. The speech alterations related to sound production may be directly related to the cognitive deficit found in the studied people and to the impairment of auditory perception found in the population.

Key-words: Kabuki Syndrome, Genetics, Language, Speech, Learning. 
INTRODUCÃO 


\section{1- INTRODUÇÃO}

A fonoaudiologia é a ciência cujo objeto de estudo é a comunicação humana e seus distúrbios. A comunicação humana envolve grandes áreas, a linguagem oral, a linguagem escrita, a articulação dos sons da fala, a voz, a fluência e a audição. Dentre as dez Grandes Áreas de Competência do fonoaudiólogo, identificadas e descritas pelo Conselho Federal de Fonoaudiologia está a de realizar o diagnóstico fonoaudiológico (CFFa, 2002).

A fonoaudiologia e a genética são ciências que se complementam e que nos últimos anos realizaram avanços no Hospital de Reabilitação de Anomalias Craniofaciais de Bauru (HRAC), da Universidade de São Paulo, campus Bauru. O trabalho conjunto dessas duas ciências muito tem contribuído para o estudo da comunicação humana e seus distúrbios nos pacientes com síndromes genéticas.

Várias são as síndromes genéticas que apresentam em seu fenótipo alterações fonoaudiologicas, dentre elas esta a síndrome de Kabuki.

A Síndrome Kabuki (SK) foi descrita recentemente por dois médicos japoneses que trabalhando de forma independente fizeram as primeiras descrições em 1981. O nome "maquiagem de Kabuki" (do inglês "kabuki make up") foi escolhido devido à aparência facial que lembra a maquiagem dos atores do teatro kabuki, uma forma tradicional de expressão teatral japonesa. Atualmente, o termo "maquiagem" (make up) não é usado para se referir à síndrome pois familiares consideraram constrangedor. 
O interesse em estudar a comunicação de indivíduos afetados pela Síndrome Kabuki surgiu a partir do contato com a literatura sobre a síndrome e da constatação da escassez de estudos sobre os achados fonoaudiológicos. Entre os mais de 300 casos descritos desde 1981, em diferentes países, poucos estudos sobre a fala e a linguagem de pessoas com SK foram encontrados segundo o relato de Defloor et al (2005).

Dentre as características da Síndrome Kabuki está o retardo mental, a perda auditiva e alterações estruturais de órgãos fonoarticulatórios que resultam em alterações da comunicação. Este dado justifica o interesse em realizar o estudo que enfocará o desempenho de comunicação de indivíduos afetados pela Síndrome Kabuki, evidencia a necessidade deste estudo para o meio científico e poderá contribuir para o desenvolvimento de ações terapêuticas para o tratamento fonoaudiológico de indivíduos portadores da Síndrome Kabuki. 


\section{REVISÃO DE LITERATURA}




\section{2 - REVISÃO DE LITERATURA}

\section{Descrição histórica da SK}

A Síndrome de Kabuki - SK (OMIM: 147920) também recebe o nome de Síndrome de Kabuki Make-up ou Síndrome de Niikawa-Kuroki, foi descrita pela primeira vez por Niikawa et al. em 1981 e por Kuroki et al. também em 1981, depois de avaliarem clinicamente 10 crianças japonesas não aparentadas (Niikawa et al. 1981, Kuroki et al. 1981).

A origem do nome "Kabuki Make-Up ou maquiagem de kabuki" surgiu a partir da semelhança dos traços faciais com a maquiagem dos atores do teatro japonês conhecido como kabuki, porém a expressão “make-up/maquiagem" foi julgada pejorativa por muitos familiares de indivíduos acometidos pela Síndrome Kabuki e não é mais utilizada.

\section{Diagnóstico e características físicas da SK}

O diagnóstico clínico da SK baseia-se em cinco características fundamentais a "Pêntade de Niikawa": face dismórfica, anomalias esqueléticas, alterações dematoglíficas, retardo mental leve a moderado, retardo do crescimento pós-natal (Gabrieli et al., 2002; Matsumoto e Niikawa, 2003 e Schoumans et al., 2005).

Sobre as características físicas, Niikawa et al (1988), Halal et al (1989), Clarke e Hall (1990), Gillis et al (1990), Philip et al (1992), Franceschini et al (1993), Hugher e 
Davis (1994), Ilyina et al (1995), Burke e Jones (1995), (Galan-Gomes et al (1995), Kobayashi e Sakuragawa (1996), Silengo et al (1996), Chu et al (1997), Tsukahara et al (1997), Lerone et al (1997), Wilson (1998), Ewart-Toland et al (1998), Fryns e Devriendt ( 1998), Makita et al (1999), Mhanni et al (1999), Kokitsu-Nakata et al (1999), Kawame et al (1999), McGaughran et al (2000), Courtens et al (2000), Donadio et al (2000), van Haelst et al (2000), Igawa et al (2000), Fong et al (2001), Selicorni et al (2001), Matsune et al (2001), Digilio et al (2001), Gabrieli et al (2002), Shotelersuk et al (2002), Kurosawa et al (2002), Hinrichs et al (2002), Mihci et al (2002), Ming et al (2003), Hou (2004), White et al (2004), Defloor et al (2005), Turner et al (2005) e Hoffman et al (2005) descreveram os achados clínicos mais importantes de cada um dos aspectos da "Pêntade de Niikawa" (características faciais típicas, anomalias dermatoglíficas, anomalias esqueléticas, déficit pondero-estatural, retardo mental) que relacionamos a seguir: Entre as características faciais típicas encontram-se a eversão da porção lateral da pálpebra inferior, sobrancelhas arqueadas com rarefação da pilificação no $1 / 3$ distal, fenda palpebral alongada, cílios longos, esclera azul, ponta nasal voltada para baixo, palato alto, fissura de palato, fistula labial inferior, orelhas dismórficas proeminentes, fistulas pré-auriculares, anomalias dentárias. As anomalias dermatoglificas são: presença de "finges pads" - coxins adiposo na face palmar de falange distal, aumento das presilhas ulnares, padrões hipotênares, ausência de trirrádio interdigital na região c e/ou d. Dentre as anomalias esqueléticas encontramos: braquidactilia de $5^{\circ}$ dígito, clinidactilia de $5^{\circ}$ dígito, escoliose, deformidade vertebral com ou sem espinha bífida, luxação congênita de quadril e luxação de patela. O déficit pondero-estatural é caracterizado principalmente pelo demorado ganho de peso quando bebês e a manutenção do percentil de crescimento mais baixo que o esperado e algumas 
crianças serão obesas na adolescência, sem qualquer alteração endócrina que possa justificar o fato. O retardo mental em geral é de grau leve a moderado.

Os autores citados descreveram as características físicas de indivíduos com SK, mas como o fizeram observando aspectos específicos da síndrome, não é possível concluir sobre a prevalência de cada uma das alterações. A partir da literatura consultada organizamos os estudos que descreveram as características clínicas de pacientes com SK. Optamos por usar o número total de casos que foram identificados na literatura (323) e, a partir deste, o número de sinais clínicos descritos em cada estudo, considerando que nem todos os estudos investigaram todas as características descritas. Por esta razão a freqüência dos sinais não correspondem ao observado nas pesquisas isoladamente.

Para melhor visualização das implicações clínicas da SK foram compilados e organizados no quadro 1 todos os aspectos da SK já investigados pelos autores citados. 
QUADRO 1: Freqüência de sinais clínicos verificados na literatura revisada .

\begin{tabular}{|c|c|c|}
\hline Manifestações Clínicas Gerais & $\begin{array}{c}\text { Sinal Clínico } \\
\text { Presente }\end{array}$ & $(\%) / 323$ \\
\hline \multicolumn{3}{|l|}{ Características Faciais Típicas } \\
\hline eversão da porção lateral da pálpebra inferior & 323 & 100 \\
\hline sobrancelhas arqueadas com rarefação da pilificação no $1 / 3$ distal & 323 & 100 \\
\hline fenda palpebral alongada & 323 & 100 \\
\hline cílios longos & 323 & 100 \\
\hline ponta nasal voltada para baixo & 323 & 100 \\
\hline palato alto & 6 & 1,86 \\
\hline fissura de palato & 13 & 4,03 \\
\hline fistula labial inferior & 8 & 2,48 \\
\hline orelhas dismórficas proeminentes & 323 & 100 \\
\hline fistulas pré-auriculares & 1 & 0,31 \\
\hline anomalias dentárias & 13 & 4,03 \\
\hline \multicolumn{3}{|l|}{ Anomalias Dematoglíficas } \\
\hline presença de "finges pads" - coxins adiposo na face palmar de falange distal & 65 & 20,12 \\
\hline aumento das presilhas ulnares & 60 & 18,58 \\
\hline padrões hipotênares & 58 & 17,96 \\
\hline ausência de trirrádio interdigital na região c e/ou d. & 60 & 18,58 \\
\hline \multicolumn{3}{|l|}{ Anomalias esqueléticas } \\
\hline braquidactilia de $5^{\circ}$ dígito & 57 & 17,65 \\
\hline clinidactilia de $5^{\circ}$ dígito & 3 & 0,93 \\
\hline Escoliose & 3 & 0,93 \\
\hline deformidade vertebral com ou sem espinha bífida & 64 & 19,81 \\
\hline luxação congênita de quadril & 1 & 0,31 \\
\hline luxação de patela & 5 & 1,55 \\
\hline \multicolumn{3}{|l|}{ Déficit pondero Estatural } \\
\hline demorado ganho de peso quando bebês & 55 & 17,03 \\
\hline manutenção do percentil de crescimento mais baixo & 67 & 20,74 \\
\hline \multicolumn{3}{|l|}{ Características cognitivas e comunicativas } \\
\hline Deficiência mental de grau leve a moderado & 96 & 29,72 \\
\hline Alterações de fala e linguagem & 14 & 4,34 \\
\hline Atraso DNPM & 5 & 1,55 \\
\hline Perda auditiva & 14 & 4,34 \\
\hline \multicolumn{3}{|l|}{ Outros achados clínicos } \\
\hline problemas neurológicos como hipotonia & 3 & 0,93 \\
\hline Convulsões & 1 & 0,31 \\
\hline microcefalia e anomalias visuais & 18 & 5,57 \\
\hline hiperextensibilidade articular & 22 & 6,81 \\
\hline anomalias cardíacas & 92 & 28,48 \\
\hline susceptibilidade a infecções & 2 & 0,62 \\
\hline Deficiência imunológica & 18 & 5,57 \\
\hline Anemia & 1 & 0,31 \\
\hline Incoordenação motora & 1 & 0,31 \\
\hline Malformações auditivas (microtia/acrotia) & 6 & 1,86 \\
\hline Alterações hepáticas e renais & 5 & 1,55 \\
\hline Problemas digestivos & 10 & 3,10 \\
\hline Problemas respiratórios & 2 & 0,62 \\
\hline Alterações estruturais no SNC & 1 & 0,31 \\
\hline
\end{tabular}

Outros achados clínicos foram descritos por Niikawa et al (1988), a partir da investigação de 62 indivíduos com SK. O pesquisador encontrou problemas neurológicos como hipotonia, convulsões, microcefalia e anomalias visuais, dos quais se destacam: hiperextensibilidade articular ( $75 \%$ dos casos), anomalias cardíacas (30 a 
$55 \%$ dos casos), perda auditiva (50\% dos casos), principalmente do tipo condutiva e susceptibilidade a infecções (60\% dos casos).

\section{Etiologia da SK}

Sugere-se que o acometimento genético da SK seja de herança autossômica dominante e a freqüência de 1/32.000 a 50.000 nascimentos. Na literatura encontram-se descritos cerca de 350 casos, sendo $1 / 3$ de não asiáticos (Niikawa et al 1988, GalanGomez et al 1995, Matsumoto e Niikawa 2003 e Defloor et al 2005).

Segundo Niikawa (1988), a condição de transmissão genética da Síndrome de Kabuki Make-up pode estar associada a quebra de um braço do cromossomo Yp11.2, sendo uma transmissão pseudoautossômica dominante, decorrente de uma nova mutação. Porém, tal condição ainda é obscura pela dificuldade de identificação e comprovação de alterações cromossômicas presentes nestes indivíduos (Olney et al 1998).

A SK, segundo Tsukahara et al (1997) e Lynch et al (1995), na maioria dos casos, é esporádica, não havendo muitas histórias de recorrência nas famílias com membros afetados; o que reforça a sugestão de Herança Autossômica Dominante com expressividade variável.

Apesar de Milunsky e Huang (2003) descreverem a duplicação 8p no cromossomo 8p22-8p23 em 1 dos 6 pacientes com SK que pesquisaram, Engelen et al (2005) não confirmaram este achado em 20 indivíduos com a síndrome que submeteram 
ao estudo citogenético, podendo concluir que esta alteração genética não é a responsável pelo diagnóstico. O diagnóstico da SK é feito a partir da avaliação clínica na maioria dos casos. Schoumans et al, 2005 também relataram que apesar da presença da microdeleção ou duplicação 8p22-23.1 encontrada por outros pesquisadores em alguns casos de SK, a investigação de 10 pacientes caucasianos por meio do mesmo método previsto no primeiro estudo excluiu essa possibilidade não encontrando a duplicação em nenhum dos indivíduos.

Matsumoto e Niikawa (2003) e Schoumans et al (2005) postulam que a etiologia da SK precisa ser mais investigada e que estudos genéticos moleculares são necessários para delineá-la, apesar da variabilidade clínica da síndrome ser bem estabelecida. Para estes autores as características da SK são variáveis, o que complica o diagnóstico dessa desordem. É possível que se encontre heterogeneidade genética entre pacientes com SK e, por esta razão, é improvável que todos os indivíduos com a síndrome tenham uma duplicação intersticial 8p22-23, mesmo porque alterações do tipo anel do cromossomo $X$, translocação $6 q / 12 q$, inversão paricêntrica $4 p$, translocação balanceada $15 q / 17 q$, duplicação 1p. já foram observadas em indivíduos com SK. O estudo citogenético molecular pela Hibridização in situ por Fluorescência (FISH), pode não ter contribuído como se esperava para o diagnóstico da SK, o que reforça a idéia de se considerar a presença de sinais clínicos típicos da síndrome.

\section{Achados cognitivos e fonoaudiológicos da SK}

Burke et al (1994), Galan-Gomez et al (1995) e Iliyna et al (1995) descreveram alguns aspectos da comunicação de indivíduos com Síndrome Kabuki. Estes autores 
caracterizaram a fala desses indivíduos como sendo pobre e de aquisição tardia, a voz em geral é grave, indistinta e hipernasal. Podem apresentar quadros de disartria e dispraxia, atrasos de linguagem e, em geral, a o nível de recepção é melhor que o de expressão.

O estudo de Toutain et al (1997), a referência de que problemas de comunicação são comuns nesta síndrome e que o quadro é muito heterogêneo. Porém não há qualquer descrição mais específica dos problemas de comunicação. Este mesmo autor afirmou que $32 \%$ dos indivíduos afetados pela Síndrome Kabuki tem perdas auditivas; que entre não asiáticos $39 \%$ tem perda auditiva e que entre asiáticos a porcentagem é de $23 \%$ de indivíduos afetados com perda auditiva. A prevalência é de perda auditiva condutiva, mas podem ser encontradas perdas neurossensorial e mista.

Upton et al (2003) avaliaram 6 crianças e todas apresentaram história de aquisição de fala e linguagem tardia. Todos apresentavam erros articulatórios e ressonância oral inadequada, incoordenação motora oral e hipotonia, má oclusão dentária e fissura de palato.

De acordo com Mervis et al (2005), pouco se sabe sobre as habilidades intelectuais e comportamentos adaptativos dos indivíduos que tem a SK, além do fato de que a maioria deles apresenta deficiência mental. Os resultados de testes psicológicos em 11 crianças e adolescentes com SK indicaram que a maior parte deles apresentam retardo mental leve e comportamentos adaptativos quase na média, podendo apresentar ainda pouca dificuldade como desatenção e hiperatividade-impulsividade e problemas leves como obsessão e ansiedade. Apenas uma criança apresentou retardo mental severo 
e comportamento adaptativo profundamente prejudicado. Uma criança também apresentou inteligência e comportamento adaptativo na média, com problemas comportamentais típicos das crianças de sua idade.

Entre os mais de 300 casos descritos desde 1981, em diferentes países, poucos estudos sobre a fala e a linguagem de pessoas com SK foram encontrados segundo o relato de Defloor et al (2005). Esses autores dirigiram estudos sobre a natureza específica do desenvolvimento comunicativo de pessoas com SK e investigaram a linguagem expressiva de crianças acometidas por esta síndrome. O objetivo do estudo foi delinear as dificuldades de linguagem de 6 crianças holandesas entre 4.4 e 10.6 anos. Por meio da análise da fala espontânea puderam verificar que todas as crianças apresentavam habilidades de linguagem expressiva defasadas, pobre habilidade morfossintática, bem como dificuldades lexicais e pragmáticas presentes enquanto o desenvolvimento fonológico era o aspecto menos afetado. 
OBJETIVO 


\section{3 - OBJETIVO}

As informações sobre os achados fonoaudiológicos da população com a SK, até o momento compiladas, são poucas e gerais.

O objetivo deste estudo, portanto, é caracterizar a linguagem oral de indivíduos portadores da Síndrome Kabuki. 
MATERIAL E MÉTODO 


\section{4 - MATERIAL E MÉTODO}

\section{Participantes}

O critério de inclusão dos sujeitos no estudo restringiu-se apenas ao fato dos mesmos consentirem na participação do mesmo e pudessem se deslocar até o HRAC caso não estivessem agendados para o atendimento de rotina no período de coleta de dados.

Foram chamados para participar deste estudo todos os pacientes registrados no HRAC com diagnóstico de SK (18). Dos 18 pacientes chamados 7 concordaram em participar do estudo, pois teriam retorno agendado e 1 sujeito concordou mesmo não tendo retorno agendado.

Durante o processo de coleta de dados, 1 dos sujeitos agendados não compareceu e outro desistiu da participação.

Cabe ressaltar que a literatura compilada registra cerca de 323 casos de pacientes com SK no mundo e, no HRAC existe o registro de 18 pacientes com a síndrome.

Fizeram parte deste estudo 6 indivíduos (33,3\% dos pacientes registrados) diagnosticados clinicamente no Setor de Genética Clínica do Hospital de Reabilitação de Anomalias Craniofaciais, da Universidade de São Paulo, de Bauru, com a SK compondo o grupo amostral, (G I) e 12 indivíduos normais pareados em relação ao sexo e à idade mental dos participantes com SK, constituindo o Grupo Controle (GC). Os 
participantes do GI encontram-se na faixa etária de 3 anos e 5 meses a 20 anos e 5 meses, sendo três do sexo feminino e três do sexo masculino.

A tabela 1 mostra a freqüência de distribuição dos indivíduos estudados, segundo o sexo e idade.

Tabela 1. Caracterização dos participantes segundo idade e sexo

\begin{tabular}{ccccccc}
\hline & \multicolumn{3}{c}{ Idade em anos e meses } \\
Sexo & \multicolumn{2}{c}{$3 \mathrm{a} / 10 \mathrm{a} 11 \mathrm{~m}$} & \multicolumn{2}{c}{$11 \mathrm{a} / 20 \mathrm{a} 11 \mathrm{~m}$} & \multicolumn{2}{c}{ TOTAL } \\
\cline { 2 - 7 } & $\mathrm{N}$ & $\%$ & $\mathrm{~N}$ & $\%$ & $\mathrm{~N}$ & $\%$ \\
\cline { 2 - 7 } Masculino & 2 & 33,3 & 1 & 16,6 & 3 & 50 \\
Feminino & 2 & 33,3 & 1 & 16,6 & 3 & 50 \\
\hline TOTAL & 4 & 66,6 & 2 & 33,2 & 6 & 100 \\
\hline
\end{tabular}

$\mathrm{N}=$ número de participantes

Os sinais clínicos descritos na literatura e investigados nos sujeitos deste estudo, foram observados e/ou levantados durante anamnese com os participantes bem como na análise do prontuário e, no quadro a seguir, apresentamos a caracterização dos mesmos, segundo os critérios de avaliação estabelecidos para o diagnóstico clínico da SK, a "Pêntade de Niikawa". Optou-se por demonstrar individualmente as características de cada participante para que se tenha uma visão real da ocorrência dos sinais e em que freqüência os mesmos aparecem. Foram observados nos participantes os seguintes sinais clínicos: 
QUADRO 2: Freqüência de sinais clínicos verificados nos participantes deste estudo.

\begin{tabular}{|c|c|c|c|c|c|c|c|c|}
\hline Manifestações Clínicas Gerais & P1 & P2 & P3 & P4 & P5 & P6 & $\Sigma$ & $\%$ \\
\hline \multicolumn{9}{|l|}{ Características Faciais Típicas } \\
\hline eversão da porção lateral da pálpebra inferior & $\mathrm{X}$ & $\mathrm{X}$ & $\mathrm{X}$ & $\mathrm{X}$ & $\mathrm{X}$ & $\mathrm{X}$ & 6 & 100 \\
\hline $\begin{array}{l}\text { sobrancelhas arqueadas com rarefação da pilificação } \\
\text { no } 1 / 3 \text { distal }\end{array}$ & $\mathrm{X}$ & $\mathrm{X}$ & $\mathrm{X}$ & $\mathrm{X}$ & $\mathrm{X}$ & $\mathrm{X}$ & 6 & 100 \\
\hline fenda palpebral alongada & $\mathrm{X}$ & $\mathrm{X}$ & $\mathrm{X}$ & $\mathrm{X}$ & $\mathrm{X}$ & $\mathrm{X}$ & 6 & 100 \\
\hline cílios longos & $\mathrm{X}$ & $\mathrm{X}$ & $\mathrm{X}$ & $\mathrm{X}$ & $\mathrm{X}$ & $\mathrm{X}$ & 6 & 100 \\
\hline esclera azul & & & & & $\mathrm{X}$ & & 1 & 16,6 \\
\hline ponta nasal voltada para baixo & $\mathrm{X}$ & $\mathrm{X}$ & $\mathrm{X}$ & $\mathrm{X}$ & $\mathrm{X}$ & $\mathrm{X}$ & 6 & 100 \\
\hline Palato alto, úvula bífida, fissura submucosa & & $\mathrm{X}$ & & & & $\mathrm{X}$ & 2 & 33,3 \\
\hline fissura de palato operado & $\mathrm{X}$ & & $\mathrm{X}$ & $\mathrm{X}$ & & & 3 & 49,8 \\
\hline malformações auditivas (microtia/acrotia) & & $\mathrm{X}$ & & & & & 1 & 16,6 \\
\hline orelhas dismórficas proeminentes & $\mathrm{X}$ & $\mathrm{X}$ & $\mathrm{X}$ & $\mathrm{X}$ & $\mathrm{X}$ & $\mathrm{X}$ & 6 & 100 \\
\hline anomalias dentárias & $\mathrm{X}$ & $\mathrm{X}$ & $\mathrm{X}$ & $\mathrm{X}$ & $\mathrm{X}$ & $\mathrm{X}$ & 6 & 100 \\
\hline \multicolumn{9}{|l|}{ Anomalias Dematoglíficas } \\
\hline $\begin{array}{l}\text { presença de "finges pads" - coxins adiposo na face } \\
\text { palmar de falange distal }\end{array}$ & $\mathrm{X}$ & $\mathrm{X}$ & $\mathrm{X}$ & & $\mathrm{X}$ & $\mathrm{X}$ & 5 & 83 \\
\hline aumento das presilhas ulnares & $\mathrm{X}$ & & $\mathrm{X}$ & $\mathrm{X}$ & & & 3 & 49,8 \\
\hline padrões hipotênares & $\mathrm{X}$ & & & $\mathrm{X}$ & & & 2 & 33,3 \\
\hline ausência de trirrádio interdigital na região c e/ou d. & & $\mathrm{X}$ & & & & & 1 & 16,6 \\
\hline \multicolumn{9}{|l|}{ Anomalias esqueléticas } \\
\hline braquidactilia de $5^{\circ}$ dígito & $\mathrm{X}$ & $\mathrm{X}$ & $\mathrm{X}$ & & & $\mathrm{X}$ & 4 & 66,4 \\
\hline clinidactilia de $5^{\circ}$ dígito & & $\mathrm{X}$ & & $\mathrm{X}$ & & & 2 & 33,3 \\
\hline Escoliose & $\mathrm{X}$ & & $\mathrm{X}$ & $\mathrm{X}$ & & & 3 & 49,8 \\
\hline deformidade vertebral com ou sem espinha bífida & $\mathrm{X}$ & $\mathrm{X}$ & & & & $\mathrm{X}$ & 3 & 49,8 \\
\hline luxação congênita de quadril & $\mathrm{X}$ & $\mathrm{X}$ & & & & & 2 & 33,3 \\
\hline luxação de patela & $\mathrm{X}$ & $\mathrm{X}$ & & & & & 2 & 33,3 \\
\hline \multicolumn{9}{|l|}{ Déficit pondero Estatural } \\
\hline demorado ganho de peso quando bebês & $\mathrm{X}$ & $\mathrm{X}$ & $\mathrm{X}$ & & & $\mathrm{X}$ & 4 & 66,4 \\
\hline manutenção do percentil de crescimento mais baixo & $\mathrm{X}$ & $\mathrm{X}$ & $\mathrm{X}$ & $\mathrm{X}$ & $\mathrm{X}$ & $\mathrm{X}$ & 6 & 100 \\
\hline \multicolumn{9}{|l|}{ Características cognitivas e comunicativas } \\
\hline deficiência mental de grau leve a moderado & $\mathrm{X}$ & $\mathrm{X}$ & $\mathrm{X}$ & $\mathrm{X}$ & $\mathrm{X}$ & $\mathrm{X}$ & 6 & 100 \\
\hline alterações de fala e linguagem & $\mathrm{X}$ & $\mathrm{X}$ & $\mathrm{X}$ & $\mathrm{X}$ & $\mathrm{X}$ & $\mathrm{X}$ & 6 & 100 \\
\hline Atraso DNPM & $\mathrm{X}$ & $\mathrm{X}$ & $\mathrm{X}$ & $\mathrm{X}$ & $\mathrm{X}$ & $\mathrm{X}$ & 6 & 100 \\
\hline \multicolumn{9}{|l|}{ Outros achados clínicos } \\
\hline perda auditiva & $\mathrm{X}$ & $\mathrm{X}$ & $\mathrm{X}$ & $\mathrm{X}$ & & & 4 & 66,4 \\
\hline perda visual & & & & $\mathrm{X}$ & & & 1 & 16,6 \\
\hline problemas neurológicos como hipotonia & $\mathrm{X}$ & $\mathrm{X}$ & $\mathrm{X}$ & $\mathrm{X}$ & $\mathrm{X}$ & $\mathrm{X}$ & 6 & 100 \\
\hline Convulsões & & & & & $\mathrm{X}$ & & 1 & 16,6 \\
\hline microcefalia e anomalias visuais & & & & $\mathrm{X}$ & $\mathrm{X}$ & & 2 & 33,3 \\
\hline hiperextensibilidade articular & $\mathrm{X}$ & & $\mathrm{X}$ & & & $\mathrm{X}$ & 3 & 49,8 \\
\hline anomalias cardíacas & & & & & $\mathrm{X}$ & & 1 & 16,6 \\
\hline susceptibilidade a infecções /deficiência imunológica & $\mathrm{X}$ & $\mathrm{X}$ & $\mathrm{X}$ & $\mathrm{X}$ & $\mathrm{X}$ & $\mathrm{X}$ & 6 & 100 \\
\hline
\end{tabular}


O grupo controle (GC) foi constituído a partir das informações sobre sexo e idade mental do grupo amostral (GI). A idade mental foi utilizada como referência para a constituição do GC, como objetivo de permitir uma análise de comparação mais próxima da realidade dos participantes com SK.

A idade mental foi estabelecida a partir da avaliação psicológica em escola de educação especial nas cidades dos participantes do estudo.

O Grupo I apresentou idade mental na faixa de $2 \mathrm{a}$ a $11 \mathrm{a}$ e $11 \mathrm{~m}$. Na tabela 2 é possível visualizar a disposição dos indivíduos com SK segundo idade mental e sexo.

Tabela 2 - Distribuição dos indivíduos com SK, segundo a idade mental e sexo.

\begin{tabular}{cccc}
\hline & Síndrome Kabuki & \\
\hline Idade mental & Masculino & Feminino & total \\
\hline 2a a 2a11m & 1 & 1 & 2 \\
4a a 4a11m & 1 & 1 & 2 \\
5a a 5a e $11 \mathrm{~m}$ & 0 & 1 & 1 \\
11a a 11a11m & 1 & 0 & 1 \\
\hline Total & 3 & 3 & 6 \\
\hline
\end{tabular}

O GC foi composto com o pareamento de indivíduos do GI, considerando o sexo e a idade mental, na razão de 2:1. Fizeram parte do GC 12 indivíduos (2N) com idade mental pareadas as idades dos sujeitos da amostra, sendo 6 do sexo feminino e 6 do sexo masculino. Os indivíduos do GC não apresentavam queixas auditivas, visuais, neurológicas ou esqueléticas. Na tabela 3 é possível visualizar a disposição do GC de acordo com idade pareada com a idade mental do GI e sexo. 
Tabela 3 - Distribuição dos indivíduos do GC, segundo a idade pareada com idade mental do GI e sexo.

\begin{tabular}{cccc}
\hline & \multicolumn{2}{c}{ Sujeitos sem SK (GC) } \\
\hline Idade mental (GI) & Masculino & Feminino & Total \\
\hline 2a a 2a11m & 2 & 2 & 4 \\
4a a 4a11m & 2 & 2 & 4 \\
5a a 5a e $11 \mathrm{~m}$ & 0 & 2 & 2 \\
11a a 11a e $11 \mathrm{~m}$ & 2 & 0 & 2 \\
\hline Total & 6 & 6 & 12 \\
\hline
\end{tabular}

\section{Procedimento de coleta de dados}

Para o desenvolvimento deste estudo, cujo objetivo foi realizar a avaliação e o diagnóstico fonoaudiológicos por meio da caracterização da comunicação de indivíduos portadores da SK, foram selecionados todos os indivíduos (19) que apresentaram o diagnóstico clínico da síndrome pela equipe de profissionais do Setor de Genética Clínica do HRAC-USP.

Os participantes foram contatados e informados sobre a realização deste estudo e seus objetivos. Participaram do estudo 5 (cinco) indivíduos que tinham retorno agendado no período de coleta de dados e 1 (um) que concordou em participar, mesmo não tendo retorno agendado. Todos foram orientados e assinaram o "Termo de Consentimento Livre e Esclarecido", segundo CNS 196/96, aprovado no CEP do HRAC, ofício n ${ }^{\circ}$ 062/2003 - UEP-CEP de 30 de maio de 2003. (ANEXO I)

Todos os procedimentos foram realizados nos indivíduos com a Síndrome Kabuki (G1) e no grupo controle (GC), por profissional habilitado em fonoaudiologia e obedecem aos critérios do Comitê de Ética do HRAC. Os procedimentos foram realizados individualmente e foram filmadas em VHS para posterior análises dos achados. 
A coleta de dados foi realizada em 4 etapas, a saber:

1) Anamnese fonoaudiológica

2) Avaliação audiológica

3) Avaliação Clínica Fonoaudiológica

4) Avaliação Fonoaudiológica Complementar

1) Anamnese Fonoaudiológica

A anamnese fonoaudiológica foi realizada para a investigação dos aspectos pré, peri e pós-natais e histórico do desempenho fonoaudiológico da criança.

A partir de um roteiro semi-estruturado para a garantia de coleta de dados padronizados, a anamnese foi realizada de forma que não restringisse as possibilidades de informações que o informante pudesse fornecer.

2) Avaliação Audiológica

Cinco participantes do GI foram submetidos à avaliação audiológica (audiometria tonal limiar / audiômetro Diagnostic Audiometer AD 27) por fonoaudióloga do setor de genética do HRAC. O objetivo da avaliação audiológica foi o de caracterizar o perfil audiológico dos indivíduos acometidos pela SK.

A classificação utilizada para a caracterização do perfil audiológico dos sujeitos foi a de Norten e Downs (1989) que prevê audição normal para limiares entre 0 e 25 , perda auditiva leve para limiares entre 26 e 40, perda auditiva moderada para limiares 
entre 41 a 70, perda auditiva severa para limiares entre 71 a 90 e perda auditiva profunda para limiares acima de 90 .

Um dos sujeitos havia realizado avaliação comportamental há menos de 3 meses no setor de fonoaudiologia e, por recusar-se a fazer a audiometria tonal limiar, foi utilizada a informação do prontuário do paciente no hospital.

3) Avaliação Clínica Fonoaudiológica

\section{1 - Avaliação da Linguagem Oral}

A avaliação clínica da linguagem oral foi realizada pela observação comportamental e física atendendo a critérios pré-estabelecidos a seguir explicados.

Para a observação comportamental da atividade comunicativa de cada participante foram considerados, em atividade lúdica (quando crianças) ou conversa espontânea, os aspectos de Intencionalidade / Habilidades Comunicativas.

Foi utilizado um Protocolo de Avaliação Fonoaudiológica para organizar os dados das avaliações. No referido Protocolo, os comportamentos comunicativos são claramente demonstrados a partir da observação dos mesmos no paciente.

Para caracterizar o grau de comprometimento observado nos indivíduos, foram adaptados os critérios de Giacheti, 1996, considerando a comunicação oral: 
- funcional ou normal, quando o indivíduo conseguiu utilizar vocabulário e frases, compreendendo e respondendo às questões formuladas; quando participou ativamente do diálogo, realizando questionamentos para a avaliadora e relatando fatos com coerência e eficácia;

- comprometimento discreto, quando o indivíduo conseguiu se comunicar, fazendo uso da comunicação oral, com frases simples e vocabulário rotineiro;

- comprometimento moderado, quando apesar do indivíduo apresentar vocabulário rotineiro era capaz de estruturar frases simples, utilizando vocábulos isolados, apesar da dificuldade em compreender e responder quando as perguntas não eram contextualizadas;

- comprometimento grave, quando utilizou vocabulário restrito, apresentou dificuldade em estruturar frases, mesmo simples, dificuldade para participar de atividades que envolviam o diálogo, aproveitamento restrito do vocabulário nas atividades propostas e uso reduzido da comunicação verbal, ininteligibilidade da comunicação oral, associada ao uso excessivo da comunicação gestual (gestos indicativos e simbólicos). Comunicação verbal praticamente ausente resultante do comprometimento semântico acentuado, associado à inabilidade para construir oralmente frases.

- grau de comprometimento extremo, quando o indivíduo não utilizou a comunicação oral para transmitir a mensagem. Não houve comportamentos comunicativos intencionais, nem interação por meio da comunicação. 
3.2 - Avaliação da Linguagem Escrita

Não foi possível avaliar este aspecto posto que os participantes não foram alfabetizados.

\section{3 - Avaliação da Fala}

Foram avaliados os aspectos relacionados à voz, a produção dos sons da fala, fluência e inteligibilidade da comunicação oral.

Consideramos a habilidade do indivíduo para utilizar a fala, analisando a produção dos sons da mesma, o tipo vocal e a fluência.

O mesmo Protocolo de Avaliação Fonoaudiológica foi utilizado para organizar os dados avaliados.

O tipo vocal está relacionado aos ajustes motores ao nível das pregas vocais e laringe e ao sistema de ressonância, de acordo com Behlau e Pontes (1995). O tipo de voz foi classificado como:

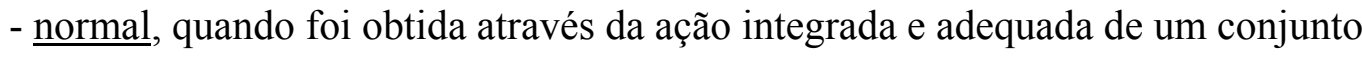
de estruturas (laringe, pregas vocais, palato mole e nariz).

- Comprometimento no sistema de ressonância, quando foi observado que o som, mesmo que corretamente produzido na laringe, não foi adequadamente modificado (voz hipernasal, voz hiponasal ou nasalidade mista). 
A produção dos sons da fala (articulação) foi avaliada a partir da emissão dos fonemas nas diferentes posições das palavras, produzidas pelos movimentos integrados dos lábios, mandíbula, língua e palato mole e considerada:

- Normal, quando a produção dos sons da fala era compatível com a idade do indivíduo;

- Alterada, quando a alteração na produção dos sons não prejudicassem totalmente a inteligibilidade;

- gravemente alterada, quando a produção dos sons se caracterizasse pelo distanciamento completo do normal, tornando a fala ininteligível.

Consideramos fluência a progressão silábica que se faz no tempo, sem interrupções. A avaliação da fluência não foi realizada posto que a amostra da fala de nenhum dos participantes foi suficiente para caracterizar os parâmetros de continuidade, velocidade na produção das palavras, controle motor na produção dos sons e coordenação pneumo-fono-articulatória, apenas em um indivíduo pôde ser observada a velocidade de fala durante a fala espontânea.

Como a inteligibilidade está relacionada à compreensão da fala por parte do ouvinte, para avaliá-la consideramos os três aspectos anteriormente avaliados da produção fonoarticulatória, para estabelecer a presença ou não de alterações neste item: o comprometimento vocal (voz), a produção do som (articulação) e a fluência. 
Quanto aos graus de comprometimento, consideramos:

- Normal, na ausência de alterações nos itens avaliados;

- Discreto, quando a alteração vocal, articulatória, fluência ou inteligibilidade não prejudicavam a transmissão eficaz da mensagem, principalmente nos casos de ressonância pouco alterado, ou ausência de produções articulatórias compensatórias.

- Moderado, quando havia entendimento da comunicação por parte do ouvinte, embora houvesse alterações significativas de ressonância associadas às produções compensatórias.

- Grave, quando a produção vocal, articulatória, ou inteligibilidade prejudicaram grande parte da transmissão da mensagem, principalmente em decorrência da alterações de ressonância, mecanismos compensatórias de produção de sons e inteligibilidade.

- Extremo, quando havia a impossibilidade eficaz da mensagem, nos aspectos vocais, articulatórios e inteligibilidade.

A avaliação da produção dos sons da fala foi realizada por meio de amostra da fala espontânea do participante e a partir da nomeação de 125 palavras balanceadas foneticamente, apresentadas em 5 desenhos temáticos (Yavas, Hernandorena e Lamprecht 1991). 
4) Avaliação Fonoaudiológica Complementar

Após a avaliação clínica cada participante foi avaliado por testes formais com o objetivo de mensurar objetivamente a avaliação da comunicação. Foram aplicados testes que avaliaram o desempenho do processamento auditivo e visual, expressão verbal e manual dos indivíduos participantes deste estudo. Ressalta-se que dos 6 sujeitos do GI, 3 foram submetidos à avaliação complementar e 3 não o foram por não haver compreensão, por parte deles, das provas aplicadas. Dos 3 que foram testados, 2 fizeram apenas parte dos testes e foram analisados os desempenhos obtidos nos mesmos.

\section{1 - TESTE ILLINOIS DE HABILIDADES PSICOLINGÜÍSTICAS (ITPA)}

Com o objetivo de avaliar as habilidades relacionadas ao processo de comunicação, utilizamos o Teste Illinois de Habilidades Psicolingüísticas (ITPA), contudo, não foi possível aplicar o teste (todo ou alguns subtestes) em todos os participantes, dada a dificuldade de compreensão da solicitação pelos mesmos.

O ITPA é um teste utilizado para avaliar habilidades relacionadas ao processo de comunicação. Engloba 12 subtestes que avaliam a recepção auditiva e visual, a memória seqüencial visual e auditiva, a associação auditiva e visual, a "closura" visual, auditiva e gramatical, a expressão verbal e manual e a combinação de sons. O Teste Illinois de Habilidades Psicolingüísticas nos permitiu quantificar e comparar o desempenho dos indivíduos estudados em tarefas que envolviam habilidades fundamentais relacionadas ao processo de comunicação. 
O teste foi elaborado por Kirk e McCarthy (1961) e fundamenta-se no referencial teórico da psicolingüística neobehaviorista, principalmente nas bases teóricas de Osgood (1957). O estudo da adaptação do ITPA à língua portuguesa foi realizado em duas teses de mestrado (Bogossian, 1975, Santos, 1977), utilizando a edição revisada, publicada em 1968 (Kirk, McCarthy \& Kirk, 1968). Informações sobre a adaptação brasileira do teste foram apresentadas em um manual para o examinador publicado por Bogossian e Santos (1977) e Bogossian (1979).

A utilização do ITPA é recomendada para avaliar crianças entre 2 e 10 anos e 11 meses de idade cronológica ou mental. O Teste Illinois de Habilidades Psicolingüísticas é composto por 12 subtestes, que avaliam as habilidades psicolingüísticas, com base nos processos de comunicação, conforme descrito por Giacheti (1996).

Subteste 1 - Recepção auditiva: tem o objetivo de avaliar a compreensão do vocabulário verbal. Consta de 50 sentenças interrogativas, de sintaxe simples, que exigem conhecimento do vocabulário. Supõe-se habilidade para relacionar o significado das sentenças.

Subteste 2 - Recepção visual: avalia a habilidade para extrair significados a partir de símbolos de natureza visual. Compreende 40 itens, cada qual com uma figuraestímulo, em uma página e quatro figuras-respostas, como alternativas, em outra página, sendo que uma delas é mais similar à figura apresentada inicialmente.

Subteste 3 - Memória seqüencial visual: avalia a habilidade de reproduzir, memorizando seqüências de figuras desprovidas de significado. Por questões práticas, a 
avaliação da memória se restringe à memória imediata. As 17 figuras apresentadas são abstratas e a reprodução das seqüências são apresentadas em progressão de complexidade. A apresentação das figuras divide-se em 25 seqüências, variando, em extensão, de 2 a 8 figuras.

Subteste 4 - Associação auditiva: objetiva avaliar a habilidade para relacionar conceitos apresentados oralmente, através de analogias verbais. Compreende 42 analogias, em que o primeiro par de elementos está associado a uma relação que deverá ser apreendida para ser utilizada no segundo par, em que está presente apenas o primeiro elemento.

Subteste 5 - Memória seqüencial auditiva: analisa a habilidade para reproduzir, memorizando seqüências de dígitos progressivamente maiores. Envolve memória imediata. Consta de vinte e oito seqüências, que variam, em extensão, de 2 a 8 dígitos.

Subteste 6 - Associação visual: objetiva avaliar a habilidade para lidar com analogias visuais. Descreve a capacidade para relacionar estímulos visualmente recebidos, através da compreensão de seu significado. As analogias requerem noções de diferentes conceitos, tais como: funcionais, associação da parte com o todo e vice-versa, similaridade, ações, entre outros.

Subteste 7 - "Closura" visual: objetiva avaliar a capacidade para identificar um estímulo comum, a partir de uma apresentação visual incompleta, reconhecendo o todo através das partes. O subteste compõe-se de 4 cenas, apresentadas separadamente, cada 
qual contendo 14 ou 15 objetos, conceitualmente semelhantes e apresentados pictoricamente dentro de um limite de tempo.

Subteste 8 - Expressão verbal: é a habilidade para expressar conceitos verbais através da apresentação de 4 objetos, escolhidos por suas características de simplicidade, familiaridade e convivência: bola, botão, envelope e cubo. A expressão verbal é avaliada pela quantidade dos conceitos emitidos, segundo um sistema de classificação elaborado pelos autores. Engloba classe ou denominação, cor, forma, composição, função, partes principais, quantificação, comparação, além de algumas outras características.

Subteste 9 - "Closura" gramatical: analisa a habilidade para fazer uso de redundâncias da linguagem oral na aquisição da sintaxe e inflexões gramaticais. Consta de 33 itens apresentados oralmente, utilizando gravuras que representam as questões expostas. Engloba o conhecimento de aspectos morfológicos, tais como: flexões de gênero, número e grau; formas verbais de modo, tempo, pessoa e voz e aspectos sintáticos da utilização de conectivos, pronomes e outros.

Subteste 10 - Expressão manual: objetiva avaliar a habilidade para exprimir uma idéia através de gestos, como forma de expressão motora. Limita-se, pela sua objetividade, a tarefas puramente gestuais, restritas à manipulação de estímulos específicos e padronizados, apresentados por meio de representação pictórica de objetos de uso comum. Composto por 15 itens, o teste é apresentado em grau crescente de dificuldade pela complexidade das ações envolvidas na representação. 
Subteste 11 - "Closura" auditiva: avalia a habilidade para completar partes ausentes de uma palavra, captada através da apresentação auditiva. Consta de 30 palavras do vocabulário rotineiro, às quais faltam fonemas ou sílabas em diferentes posições e o avaliado deverá identificar a palavra, emitindo-a de forma completa.

Subteste 12 - Combinações de sons: permite a avaliação da integração dos processos associativos e encontra-se dividido em 3 seções, sendo que, na primeira, as palavras são apresentadas sob forma de fonemas separados e o indivíduo deve apontar as figuras que representam as palavras anteriormente apresentadas. Na segunda seção, também são apresentados os sons de palavras com significado e o avaliado deve verbalizar a palavra apresentada pelo avaliador e, por último, são apresentados sons que compõem vocábulos sem significado. É a capacidade de integrar auditivamente partes isoladas em unidades completas, dotadas ou não de significado.

Após a aplicação e contagem dos pontos em cada subteste (os que foram possíveis de se realizar), utilizamos 3 valores distintos e previstos pelo teste:

- escore bruto obtido: conseguido diretamente em cada subteste (somatória dos pontos). Utilizado para comparações entre grupos e para efetuar cálculos de correlações;

- escore escalar obtido: conseguido através de tabelas específicas de acordo com a idade cronológica, apresentadas no manual de utilização do teste. Para cada valor do escore bruto, existe um valor de escore escalar que leva em consideração a idade cronológica do indivíduo avaliado. Em função desta relação, é o valor mais importante para o desempenho de cada indivíduo avaliado; 
- idade psicolingüística (IPL) obtida: é o valor conseguido a partir do escore bruto obtido em cada subteste. É encontrado também em tabela específica apresentada no manual de utilização do teste;

\section{Procedimento de análise dos dados}

Os dados da avaliação clínica e complementar realizada foram tratados de forma descritiva e comparados entre o GI e GC, considerando, na avaliação clínica, o desempenho dos participantes em cada prova e, na avaliação complementar, os escores bruto, escalar, idade psicolingüística. 


\section{RESULTADOS}




\section{5- RESULTADOS}

Neste capítulo apresentamos os resultados obtidos por meio da entrevista, avaliação fonoaudiológica clínica e avaliação fonoaudiológica complementar previstas no procedimento de coleta de dados.

\section{Primeira etapa: Anamnese fonoaudiológica}

As informações levantadas na anamnese nos permitiram caracterizar com mais detalhes os sujeitos participantes deste estudo.

Os informantes foram questionados a partir de um roteiro semi-estruturado para garantir a coleta de dados padronizados, porém foi oferecida abertura para que o mesmo pudesse fornecer informações sem quaisquer restrições. As questões eram relacionadas à existência de queixa fonoaudiológica, sobre o desenvolvimento da comunicação e como a mesma acontece na atualidade, as dificuldades de comunicação encontradas, as habilidades comunicativas, o desenvolvimento global, dados comportamentais de rotina e sobre a SK.

Para melhor descrição dos sujeitos do GI, antes de cada quadro com os dados da anamnese foram apresentados informações quando a idade, sexo e sobre a intervenção fonoaudiológica a que foram submetidos até então. Os quadros seguintes (3 a 8) referem-se às informações dos participantes $(\mathrm{G} \mathrm{I})$ coletadas na anamnese. 
P1, sexo feminino, na data da avaliação tinha 14 anos e 1 mês. P1 fez fonoterapia há 2 anos, tendo sessões de 20 minutos a cada 20 dias, na instituição de educação especial que freqüentava na época, mas a mãe referiu não ter visto resultado e nem conhecer o profissional que trabalhava com ela. Atualmente freqüenta uma instituição de educação especial no período da tarde. O quadro 3 refere-se aos dados de anamnese de P1.

Quadro 3. Descrição das informações da anamnese fonoaudiológica de P1.

\begin{tabular}{|c|l|}
\hline \multicolumn{1}{|c|}{ P1 } & Sexo feminino, 14 anos e 1 mês \\
\hline Queixa & "Ela não fala, ela "canta" o tempo todo".(sic-mãe) \\
\hline Antecedentes Familiares & Não existe consangüinidade nem recorrência familial da SK \\
\hline Condições de Nascimento & $\begin{array}{l}\text { Mãe não soube referir detalhes, mas lembra que achou a } \\
\text { criança diferente, muito molinha. }\end{array}$ \\
\hline Informações pós-natal & $\begin{array}{l}\text { Percebeu que tinha algum problema, dificuldade para } \\
\text { alimentar, fissura, muitas infecções de ouvido, baixa } \\
\text { resistência imunológica. }\end{array}$ \\
\hline $\begin{array}{c}\text { Desenvolvimento } \\
\text { NeuroPsicoMotor }\end{array}$ & $\begin{array}{l}\text { Não sabe referir datas, mas lembra que a filha demorou mais } \\
\text { que os irmãos para sentar, engatinhar, andar, teve dificuldade } \\
\text { para adquirir o controle de esfíncter vesical e anal. }\end{array}$ \\
\hline $\begin{array}{c}\text { Aspectos de } \\
\text { desenvolvimento da } \\
\text { linguagem }\end{array}$ & $\begin{array}{l}\text { Demorou bastante pra começar a falar as primeiras palavras } \\
\text { com significado. Vocaliza muito e faz muitos gestos. "Ela faz } \\
\text { como se tivesse falando, mas não dá pra entender nada do que } \\
\text { diz, só eu entendo ela". (sic-mãe). Ela não fala muita coisa, } \\
\text { mas dá pra entender o que ela quer pelos gestos, ela faz } \\
\text { mímica. Ela parece saber tudo, compreende tudo o que } \\
\text { acontece. (sic-mãe) }\end{array}$ \\
\hline
\end{tabular}


P2, sexo masculino, na data da avaliação tinha 5 anos e 6 meses. Faz fonoterapia há 3 anos em sessões semanais de 20 minutos, a mãe refere não saber o que é realizado nas sessões e nem vê resultados. Atualmente freqüenta escola de educação infantil no período da manhã e, segundo a professora apresenta pouca dificuldade em acompanhar a turma. O quadro 4 mostra os dados de anamnese de P2.

Quadro 4. Descrição das informações da anamnese fonoaudiológica de P2.

\begin{tabular}{|c|l|}
\hline \multicolumn{1}{|c|}{ P2 } & Sexo masculino, 5 anos e 6 meses \\
\hline Queixa & "Ele fala pouco, fala palavras pela metade" \\
\hline Antecedentes Familiares & Não existe consangüinidade nem recorrência familial da SK \\
\hline Condições de Nascimento & Sem intercorrências, a termo, cesárea, nasceu bem, chorou, \\
\hline $\begin{array}{c}\text { Informações pós-natal } \\
\text { Com 4 meses foi encaminhado ao Centrinho em Itararé, com } \\
\text { fissura submucosa e malformação na orelha esquerda, muitas } \\
\text { infecções, baixa resistência imunológica. }\end{array}$ \\
\hline $\begin{array}{c}\text { Desenvolvimento } \\
\text { NeuroPsicoMotor }\end{array}$ & $\begin{array}{l}\text { Era muito mole até os 5 meses, ficou 9 meses engessado (pé } \\
\text { torto), engatinhou com 1 ano e andou com 1 ano e 2 meses }\end{array}$ \\
\hline $\begin{array}{c}\text { Aspectos de } \\
\text { desenvolvimento da } \\
\text { linguagem }\end{array}$ & $\begin{array}{l}\text { Começou a usar palavras com significado com mais de 2 anos. } \\
\text { Hoje usa frases curtas, até 3 palavras, fala palavras pela } \\
\text { metade, as pessoas não entendem, só os pais. Não usa gestos, } \\
\text { se atrapalha um pouco pra narrar fatos, usa palavras isoladas. }\end{array}$ \\
\hline
\end{tabular}


P3, sexo masculino, tinha 4 anos e 1 mês na data da avaliação. No ano de 2004 fez fonoterapia em sessões semanais de 20 minutos por 9 ou 10 meses, parou quando começou a freqüentar uma instituição de educação especial duas vezes por semana para estimulação mas não soube referir que tipo de estimulação o filho recebe lá. O quadro 5 mostra os dados da anamnese de P3.

Quadro 5. Descrição das informações da anamnese fonoaudiológica de P3.

\begin{tabular}{|c|l|}
\hline \multicolumn{1}{|c|}{ P3 } & Sexo masculino, 4 anos e 1 mês \\
\hline Queixa & "Ele não fala nada, não se comunica” \\
\hline Antecedentes Familiares & Não existe consangüinidade nem recorrência familial da SK \\
\hline Condições de Nascimento & $\begin{array}{l}\text { Nasceu a termo, parto cesariano. Criança nasceu muito mole, } \\
\text { não chorou }\end{array}$ \\
\hline $\begin{array}{c}\text { Informações pós-natal } \\
\text { Apresentou muitas infecções, baixa resistência imunológica, } \\
\text { dificuldade para alimentar. }\end{array}$ \\
\hline $\begin{array}{c}\text { Desenvolvimento } \\
\text { Aspectos de } \\
\text { desenvolvimento da } \\
\text { linguagem }\end{array}$ & $\begin{array}{l}\text { Atraso geral, andou com 2 anos e 7 meses } \\
\text { que não fala nada, só procura outra pessoa quando precisa e algo } \\
\text { atenção do outro para o que ele deseja. Só mostra as } \\
\text { necessidades por meio de gestos, apontando para o objeto } \\
\text { desejado. }\end{array}$ \\
\hline
\end{tabular}


P4, sexo masculino, tinha 20 anos e 5 meses na data da avaliação. Nunca fez fonoterapia. Freqüentou instituição de educação especial para deficientes visuais e atualmente fica a maior parte do tempo em casa. O quadro 6 mostra os dados de anamnese de $\mathrm{P} 4$.

Quadro 6. Descrição das informações da anamnese fonoaudiológica de P4.

\begin{tabular}{|c|l|}
\hline \multicolumn{1}{|c|}{ P4 } & Sexo masculino, 20 anos e 5 meses \\
\hline Queixa & "Ele não fala muito bem e também não sabe ler nem escrever" \\
\hline Antecedentes Familiares & Não existe consangüinidade nem recorrência familial da SK \\
\hline Condições de Nascimento & Sem intercorrências. \\
\hline $\begin{array}{c}\text { Informações pós-natal } \\
\text { Muitas infecções, baixa resistência imunológica, complicações } \\
\text { alimentares }\end{array}$ \\
\hline $\begin{array}{c}\text { NeuropsicoMotor } \\
\text { Aspectos de } \\
\text { desenvolvimento da } \\
\text { linguagem }\end{array}$ & $\begin{array}{l}\text { Atraso no desenvolvimento motor, demorou para sentar e } \\
\text { andar }\end{array}$ \\
\hline $\begin{array}{l}\text { Demorou um pouco para começar a falar. Hoje se comunica } \\
\text { bem, fala suas necessidades, desejos, narra fatos, as vezes não } \\
\text { dá pra entender bem o que ele fala. Não sabe ler ou escrever. }\end{array}$ \\
\hline
\end{tabular}


P5, sexo feminino, tinha 3 anos e 5 meses na data da avaliação. Procurou atendimento fonoaudiológico recentemente, está em terapia para aprender a falar (sic mãe). Freqüenta escola de educação especial onde recebe estimulação global. O quadro 7 mostra os dados da anamnese de P5.

Quadro 7. Descrição das informações da anamnese fonoaudiológica de P5.

\begin{tabular}{|c|l|}
\hline \multicolumn{1}{|c|}{ P5 } & Sexo feminino, 3 anos e 6 meses \\
\hline Queixa & "Minha filha fala pouco para a idade." (sic-mãe) \\
\hline Antecedentes Familiares & Não existe consangüinidade nem recorrência familial da SK \\
\hline Condições de Nascimento & $\begin{array}{l}\text { Cesária, a termo, 3.480g e 48cm, não apresentando dilatação } \\
\text { (sic). }\end{array}$ \\
\hline $\begin{array}{c}\text { Informações pós-natal } \\
\text { Dois episódios de crise convulsiva, Infecções recorrentes, } \\
\text { baixa resistência imunológica, lacrimejamento e secreção } \\
\text { ocular, sendo realizada intervenção cirúrgica para desobstrução } \\
\text { dos ductos lacrimais aos 2a4m, portadora de alteração cardíaca } \\
\text { congênita e pés e mãos edemaciados (sic). }\end{array}$ \\
\hline $\begin{array}{c}\text { Desenvolvimento Motor } \\
\text { Geral }\end{array}$ & $\begin{array}{l}\text { Sentou sem apoio com 1 ano, engatinhou com 1a3m e andou } \\
\text { com 1a7m, não adquiriu controle de esfíncter vesical e anal ate } \\
\text { a presente data (sic). }\end{array}$ \\
\hline $\begin{array}{c}\text { Aspectos de } \\
\text { desenvolvimento da } \\
\text { linguagem }\end{array}$ & $\begin{array}{l}\text { Falou "ta" com 1 ano e "tatá" com 2 anos. } \\
\text { Atualmente não fala nada e apresenta emissões ininteligíveis } \\
\text { associadas a gestos. Compreensão adequada (sic). }\end{array}$ \\
\hline
\end{tabular}


P6, sexo feminino, tinha 6 anos e 11 meses na data da avaliação. Nunca fez fonoterapia e não freqüenta escola. O quadro 8 mostra os dados da anamnese de P6.

Quadro 8. Descrição das informações da anamnese fonoaudiológica de P6.

\begin{tabular}{|l|l|}
\hline P6 & Sexo feminino, 6 anos e 11 meses \\
\hline Queixa & "Ela não fala" \\
\hline Antecedentes Familiares & Não existe consangüinidade nem recorrência familial da SK \\
\hline Condições de Nascimento & A termo, cesárea, criança não chorou, muito mole \\
\hline Informações pós-natal & $\begin{array}{l}\text { Muitas infecções, baixa resistência imunológica, dificuldades } \\
\text { alimentares, tirou a sonda de alimentação há 1 mês. }\end{array}$ \\
\hline $\begin{array}{l}\text { Desenvolvimento } \\
\text { NeuroPsicoMotor }\end{array}$ & $\begin{array}{l}\text { Atraso no desenvolvimento motor, andou com 3 anos ainda } \\
\text { não tem controle de sfincter vesical ou anal. }\end{array}$ \\
\hline $\begin{array}{l}\text { Aspectos } \\
\text { desenvolvimento } \\
\text { linguagem }\end{array}$ & $\begin{array}{l}\text { de } \\
\text { da }\end{array}$ \\
\hline
\end{tabular}

Os dados da anamnese evidenciaram que $100 \%$ dos casos estudados apresentam queixa fonoaudiológica e 50\% deles (P1, P2 e P3) fizeram fonoterapia em sessões semanais, ou a cada 20 dias em um dos casos, por 20 minutos. Dois sujeitos (P5 e P6) nunca fizeram fonoterapia e um deles (P4) procurou por atendimento fonoaudiológico recentemente, quando a criança já estava com 3 anos e 5 meses e falava pouco para a idade. 


\section{Segunda etapa: Avaliação audiológica}

A avaliação audiológica nos permitiu traçar o perfil audiológico dos sujeitos deste grupo acometidos pela SK (GI). O exame realizado evidenciou que $66,6 \%$ da amostra é acometido por perda auditiva. Destes, 75\% apresentaram perda auditiva do tipo condutiva e $25 \%$ apresentaram perda mista. Dois indivíduos, 33,3\% da amostra, apresentaram audição normal.

O resultado da avaliação audiológica pode ser visualizado na tabela 4.

Tabela 4. perfil audiológico dos participantes deste estudo

\begin{tabular}{cl}
\hline Participante & \multicolumn{1}{c}{ Perfil Audiológico } \\
\hline P1 & Perda auditiva mista moderada a severa bilateral \\
& Perda auditiva condutiva leve na orelha direita, orelha esquerda apresenta \\
P2 & malformação. \\
P3 & Perda auditiva moderada por avaliação comportamental \\
P4 & Perda auditiva condutiva moderada bilateral \\
P5 & Audição normal \\
P6 & Audição normal \\
\hline
\end{tabular}

Foi identificado 1 sujeito $(16,6)$ do GI com perda auditiva e visual associada. A tabela 5 mostra a freqüência de participantes do estudo segundo sexo e acometimento auditivo e visual associado. 
Tabela 5. Caracterização dos participantes do GI segundo sexo e comprometimento auditivo e visual

\begin{tabular}{ccccccccccc}
\hline \multirow{2}{*}{ Sexo } & $\begin{array}{c}\text { Perda } \\
\text { auditiva }\end{array}$ & \multicolumn{2}{c}{$\begin{array}{c}\text { Perda } \\
\text { visual }\end{array}$} & $\begin{array}{c}\text { Perda auditiva e } \\
\text { visual associada }\end{array}$ & $\begin{array}{c}\text { Sem perda } \\
\text { auditiva ou visual }\end{array}$ & \multicolumn{2}{c}{ TOTAL } \\
\cline { 2 - 12 } Masculino & $\mathrm{N}$ & $\%$ & $\mathrm{~N}$ & $\%$ & $\mathrm{~N}$ & $\%$ & $\mathrm{~N}$ & $\%$ & $\mathrm{~N}$ & $\%$ \\
\cline { 2 - 12 } & 3 & 49,8 & 0 & 0 & 1 & 16,6 & 0 & 0 & 4 & 66,6 \\
\cline { 2 - 12 } Feminino & 1 & 16,6 & 0 & 0 & 0 & 0 & 1 & 16,6 & 2 & 33,3 \\
\hline TOTAL & 4 & 66,6 & 0 & 0 & 1 & 16,6 & 1 & 16,6 & 6 & 100 \\
\hline
\end{tabular}

$\mathrm{N}=$ número de participantes

Os sujeitos do GC não apresentaram perda auditiva ou visual por ser este um dos critérios de inclusão na amostra. 


\section{Terceira etapa: Avaliação fonoaudiológica clínica}

Aqui foram apresentados e discutidos os resultados obtidos na Avaliação Clínica Fonoaudiológica dos sujeitos deste estudo que podem ter melhor visualização nas Tabelas 6 a 10 .

Os resultados do GI e GC foram mostrados na mesma tabela para facilitar a comparação de desempenho entre os grupos.

O grau de comprometimento da linguagem oral foi determinado levando em consideração o desempenho em atividades comunicativas segundo os aspectos avaliados do Protocolo de Avaliação Fonoaudiológica (Anexo III) quanto à habilidade comunicativa, fonologia, semântica, sintaxe e pragmática. De acordo com o desempenho apresentado, a comunicação oral foi considerada normal ou funcional, com comprometimento discreto, comprometimento moderado, comprometimento grave e comprometimento extremo.

No GI um sujeito do sexo masculino apresentou comprometimento discreto da comunicação, um sujeito do sexo masculino comprometimento moderado, um sujeito do sexo feminino comprometimento grave e um sujeito do sexo masculino e dois do sexo feminino apresentaram comprometimento extremo.

Optou-se por descrever o desempenho de cada participante do GI antes da apresentação da tabela com dados gerais. 
$\mathrm{Na}$ avaliação da comunicação oral P1 apresentou comprometimento grave. Suas habilidades comunicativas caracterizam-se por usar preferencialmente gestos ou ações motoras com função comunicativa (mímica facial, movimento de olhos ou qualquer parte do corpo); responde quando chamado pelo nome; foi capaz de contar fatos através de gestos acompanhados de vocalizações, compreendeu frases simples, sua fala é ininteligível e constitui-se apenas de palavras muito mal articuladas, difíceis de serem compreendidas. Não foi possível avaliar a fonologia pelo fato de não haver fala inteligível constituída, apenas vocalizações. Quanto à sintaxe, foi observado que o sujeito tem dificuldade para compreender ordens complexas e a fala não se caracteriza pelo uso adequado das estruturas sintáticas, posto que P1 apenas fez vocalizações. No aspecto semântico, percebe-se pela expressividade gestual a compreensão da fala do interlocutor que P1 tem repertório lexical pobre, identificando objetos do cotidiano nas figuras apresentadas, identifica atributos de objetos do objeto/evento, nomeia (gesto representativo acompanhado de vocalização) objetos do cotidiano, identifica a função dos objetos. Quanto ao aspecto pragmático, P1 faz contato visual, tem intenção comunicativa iniciando diálogo por meio de vocalizações e gestos indicativos, responde perguntas, mantém troca de turno, expressa idéias/necessidades.

P2, na mesma avaliação, mostrou comprometimento moderado. Suas habilidades comunicativas caracterizaram-se por utilizar preferencialmente a fala, apesar de ininteligível. P2 reponde quando chamado, narra fatos e episódios de maneira objetiva, com poucas palavras e compreende narrativa simples. No aspecto de fonologia foi possível observar na produção restrita de P2 que ele faz muitas omissões de sons, comprometendo a inteligibilidade da fala, a produção do som é inadequada. Quanto à sintaxe, observou-se que ele compreende ordens simples, mas não faz uso de estruturas 
frasais, pois utiliza, no máximo, 2 palavras justapostas na comunicação. No aspecto semântico, percebe-se pela atividade na brincadeira e em conversa espontânea que P2 tem repertório lexical pobre, que identifica objetos do cotidiano e atributos do objeto/evento, nomeia e identifica a função dos objetos do cotidiano, apresenta verbalmente a função dos objetos apesar da dificuldade de inteligibilidade da fala que apresenta. Quanto ao aspecto pragmático, P2 faz contato visual, tem intenção comunicativa iniciando diálogo por meio de vocalizações e gestos indicativos, responde perguntas, mantém troca de turno e expressa idéias/necessidades.

P3 e P6, na mesma avaliação, mostraram comprometimento extremo da comunicação oral . Foi observado extremo comprometimento das habilidades comunicativas destes participantes na medida em que os mesmos não utilizaram a comunicação oral para transmitir mensagens e não apresentaram comportamentos comunicativos intencionais, nem interação por meio da comunicação.

P5 também mostrou comprometimento extremo da comunicação oral, com ausência de fala, apresentou dificuldade na compreensão de frases simples, predomínio da comunicação gestual (poucos gestos indicativos), com expressão facial, houve pobre interação com o interlocutor.

P4 apresentou comprometimento discreto. Suas habilidades comunicativas caracterizaram-se pelo uso preferencial da fala que é inteligível. P4 foi capaz de narra fatos e episódios e de compreender narrativas simples. Apresentou poucas inadequações quanto à fonologia, caracterizadas principalmente por omissões de fonemas. Quanto à sintaxe, foi possível observar que a construção frasal é simples, mas adequada. No 
aspecto semântico, observou-se que P4 identifica objetos e atributos de objetos do objeto/evento, nomeia objetos do cotidiano e identifica suas funções e descreve objetos ou eventos. Quanto ao aspecto pragmático, P4 não apresentou alterações relevantes, ele fez e manteve contato de olho, iniciou diálogo, manteve o tema proposto pelo interlocutor, manteve troca de turnos e expressou idéias/necessidades.

Os sujeitos do GC apresentaram, na sua maioria, (91,7\%) habilidades comunicativas caracterizadas pelo uso preferencial da fala inteligível. Foram capazes de narrar fatos e episódios e de compreender narrativas simples. Um indivíduo deste grupo $(8,3 \%)$ apresentou inadequações quanto à fonologia, caracterizadas principalmente por trocas de fonemas $/ \mathrm{k} /$ por $/ \mathrm{t} /, / \mathrm{s} /$ por $/ \mathrm{t} / \mathrm{e} / \mathrm{p} /$ por $/ \mathrm{k} /$ assistematicamente. Quanto à sintaxe, foi possível observar que a construção frasal é adequada para a idade avaliada. No aspecto semântico, observou-se que eles identificaram objetos e atributos de objetos do objeto/evento, nomearam objetos do cotidiano e identificaram suas funções e descreveram objetos ou eventos. Quanto ao aspecto pragmático, não apresentaram alterações relevantes, fizeram e mantiveram contato de olho, iniciaram diálogo, mantiveram o tema proposto pelo interlocutor, mantiveram troca de turnos e expressaram idéias/necessidades.

Na tabela 6 apresentamos o grau de comprometimento da comunicação oral dos sujeitos deste estudo nos aspectos de habilidade comunicativa, fonológicos, semânticos, sintáticos e pragmáticos dos dois grupos estudados. Observando que a porcentagem total na coluna refere-se ao GI e GC individualmente. 
Tabela 6. Presença e ausência de comprometimento e grau de comprometimento da linguagem oral nos aspectos de habilidade comunicativa, fonológicos, semânticos, sintáticos e pragmáticos do GI e GC.

\begin{tabular}{|c|c|c|c|c|c|c|c|c|c|c|c|c|}
\hline \multirow{3}{*}{$\begin{array}{c}\text { Presença/ausência } \\
\text { de } \\
\text { Comprometimento }\end{array}$} & \multirow{2}{*}{\multicolumn{2}{|c|}{$\begin{array}{c}\text { Sem } \\
\text { alterações. }\end{array}$}} & \multirow{2}{*}{\multicolumn{2}{|c|}{ Discreto }} & \multirow{2}{*}{\multicolumn{2}{|c|}{ Moderado }} & \multirow{2}{*}{\multicolumn{2}{|c|}{ Grave }} & \multirow{2}{*}{\multicolumn{2}{|c|}{ Extremo }} & \multirow{2}{*}{\multicolumn{2}{|c|}{ TOTAL }} \\
\hline & & & & & & & & & & & & \\
\hline & $\mathrm{N}$ & $\%$ & $\mathrm{~N}$ & $\%$ & $\mathrm{~N}$ & $\%$ & $\mathrm{~N}$ & $\%$ & $\mathrm{~N}$ & $\%$ & $\mathrm{~N}$ & $\%$ \\
\hline GI & 0 & 0 & 1 & 16,6 & 1 & 16,6 & 1 & 16,6 & 3 & 49,9 & 6 & 100 \\
\hline $\mathrm{GC}$ & 11 & 91,7 & 1 & 8,3 & 0 & 0 & 0 & 0 & 0 & 0 & 12 & 100 \\
\hline
\end{tabular}

A análise do uso que o indivíduo faz da comunicação (a pragmática) é fundamental para identificar o quanto ele interage e se comunica através da fala, mais que a análise da forma e do conteúdo, como foram mostrados até aqui.

Todos os sujeitos do GI (100\%) apresentaram alterações na funcionalidade da lingaugem oral, sendo que $3(50 \%)$, apresentaram poucas alterações no aspecto pragmático da linguagem, enquanto $3(50 \%)$ apresentaram alterações graves no mesmo aspecto. A dificuldade maior para os sujeitos com pouca alteração da funcionalidade da comunicação restringe-se à manutenção do diálogo ou tema da conversa, principalmente relacionados à narrativa de fatos/acontecimentos.

A tabela 7 mostra a distribuição dos indivíduos segundo a alteração do aspecto funcional da linguagem oral. A porcentagem descrita nas colunas GI e GC referem-se ao grupo especificamente e não à somatória dos mesmos. 
Tabela 7. Distribuição dos indivíduos segundo a alteração do aspecto funcional da linguagem oral.

\begin{tabular}{|c|c|c|c|c|c|c|c|c|}
\hline \multirow[t]{2}{*}{ Comportamentos avaliados } & \multicolumn{2}{|c|}{ GI } & \multicolumn{2}{|c|}{$\begin{array}{l}\text { TOTAL GI } \\
\text { por comport. }\end{array}$} & \multicolumn{2}{|c|}{ GC } & \multicolumn{2}{|c|}{$\begin{array}{l}\text { TOTALGC } \\
\text { por comport. }\end{array}$} \\
\hline & $\mathrm{N}$ & $\%$ & $\mathrm{~N}$ & $\%$ & $\mathrm{~N}$ & $\%$ & $\mathrm{~N}$ & $\%$ \\
\hline Faz contato visual & 3 & 50 & & & 12 & 100 & & \\
\hline Não faz contato visual & 3 & 50 & 6 & 100 & 0 & 0 & 12 & 100 \\
\hline Mantém contato visual & 3 & 50 & & & 12 & 100 & & \\
\hline Não mantém contato visual & 3 & 50 & 6 & 100 & 0 & 0 & 12 & 100 \\
\hline Inicia diálogo & 3 & 50 & & & 11 & 91,6 & & \\
\hline Não inicia diálogo & 3 & 50 & 6 & 100 & 1 & 8,3 & 12 & 100 \\
\hline Mantém diálogo/tema & 2 & 33,3 & & & 8 & 66,6 & & \\
\hline Não mantém diálogo/tema & 4 & 66,6 & 6 & 100 & 4 & 33,3 & 12 & 100 \\
\hline Mantém troca de turno & 3 & 50 & & & 12 & 100 & & \\
\hline Não mantém troca de turno & 3 & 50 & 6 & 100 & 0 & 0 & 12 & 100 \\
\hline Expressa idéias/necessidades & 3 & 50 & & & 8 & 66,6 & & \\
\hline Não expressa idéias/necessidades & 3 & 50 & 6 & 100 & 4 & 33,3 & 12 & 100 \\
\hline
\end{tabular}




\section{Avaliação da Fala}

Os resultados da avaliação da fala evidenciaram a presença e a variabilidade das manifestações clínicas fonoaudiológicas dos indivíduos com SK participantes deste estudo.

A seguir, detalhamos os resultados obtidos em cada um dos aspectos avaliados em fala.

\section{- Comportamento vocal}

Quanto ao tipo vocal, verificamos no GI que 3 participantes apresentaram leve ou moderada hipernasalidade, (P1, P2 e P4) o que não chegou a prejudicar a inteligibilidade da fala. Um dos participantes também apresentou voz rouca, grave e soprosa (P1) e dois também apresentaram voz aguda (P2 e P4). Três participantes não puderam ser avaliados neste aspecto por apresentarem reduzida ou ausente produção vocal.

No GC não foram observadas alterações de ressonância e, 4 sujeitos apresentaram voz rouca.

O comprometimento da fala considerando o tipo vocal e ressonância dos grupos avaliados foi mostrado na tabela 8 . A somatória total dos indivíduos não se apresenta como nas outras tabelas porque os indivíduos apresentam alterações vocais associadas. 
Tabela 8. Grau de comprometimento da fala considerando o tipo vocal e o sistema de ressonância (hipernasal) dos grupos avaliados.

\begin{tabular}{|c|c|c|c|c|c|c|c|c|c|c|c|c|c|}
\hline \multirow{2}{*}{$\begin{array}{l}\text { Tipo vocal } \\
\text { Grupos }\end{array}$} & \multicolumn{2}{|c|}{ rouca } & \multicolumn{6}{|c|}{ Hipernasal } & \multicolumn{2}{|c|}{ aguda } & \multicolumn{2}{|c|}{$\begin{array}{c}\text { Não } \\
\text { avaliado }\end{array}$} & \multirow{2}{*}{ TOTAL } \\
\hline & $\mathrm{N}$ & $\%$ & $\mathrm{~N}$ & $\%$ & $\mathrm{~N}$ & $\%$ & $\mathrm{~N}$ & $\%$ & $\mathrm{~N}$ & $\%$ & $\mathrm{~N}$ & $\%$ & \\
\hline GI & 1 & 16,6 & 1 & 16,6 & 3 & 50 & 1 & 16,6 & 2 & 33,3 & 3 & 50 & 100 \\
\hline GC & 3 & 24,9 & 0 & 0 & 0 & 0 & 2 & 16,6 & 1 & 8,3 & 0 & 0 & 100 \\
\hline
\end{tabular}

No GC, os 4 sujeitos que apresentaram voz rouca não relataram histórico de abuso vocal nem recorrentes processos infecciosos.

- A produção dos sons da fala

A articulação dos sons da fala foi verificada em conversa espontânea e em provas de nomeação utilizando as figuras temáticas de Yavas, 1991.

Todos os sujeitos (100\%) do GI apresentaram alteração na produção dos sons da fala enquanto 3, de 12, (24,9\%) do GC apresentaram alterações desta ordem.

No GI, um dos participantes com fissura de lábio e palato operado apresentou a articulação dos sons pouco alterada caracterizado pela imprecisão articulatória, não comprometendo a inteligibilidade da fala, um participante com fissura submucosa apresentou alteração na produção dos sons da fala, também caracterizada pela imprecisão articulatória dos sons da fala comprometendo a inteligibilidade e um com fissura de palato operado apresentou graves alterações, comprometendo muito a inteligibilidade da fala, três participantes, um com fissura transforame à esquerda 
operado, um com úvula bífida e um sem fissura não puderam ser avaliados neste aspecto por apresentarem ausência de fala ou reduzida amostra.

No GC, 9 sujeitos $(75,1 \%)$ não apresentaram alterações na produção dos sons da fala e 3 sujeitos $(24,9 \%)$ apresentaram pouca alteração. As alterações encontradas nos 3 sujeitos referem-se a distorção na produção dos fonemas /s/, /z/, /J/, e / / e projeção anterior da língua na produção do /t/, /d/, /n/ e /1/, alterações estas de ordem fonética.

Os achados referentes à produção dos sons da fala dos GI e GC podem ser observados na tabela 9. A coluna TOTAL refere-se à somatória de cada grupo específico.

Tabela 9. Grau de comprometimento da fala considerando a articulação dos sons da fala em cada grupo avaliado.

\begin{tabular}{|c|c|c|c|c|c|c|c|c|c|c|}
\hline \multirow[t]{2}{*}{ articulação } & \multicolumn{2}{|c|}{ Normal } & \multicolumn{2}{|c|}{$\begin{array}{l}\text { Pouco } \\
\text { alterado }\end{array}$} & \multicolumn{2}{|c|}{ alterado } & \multicolumn{2}{|c|}{$\begin{array}{l}\text { Gravemente } \\
\text { alterado }\end{array}$} & $\begin{array}{c}\text { Não } \\
\text { avaliado }\end{array}$ & TOTAL \\
\hline & $\mathrm{N}$ & $\%$ & $\mathrm{~N}$ & $\%$ & $\mathrm{~N}$ & $\%$ & $\mathrm{~N}$ & $\%$ & $\mathrm{~N} \quad \%$ & $\%$ \\
\hline GI & 0 & 0 & 1 & 16,6 & 1 & 16,6 & 1 & 16,6 & 50 & 100 \\
\hline $\mathrm{GC}$ & 9 & 75,1 & 3 & 24,9 & 0 & 0 & 0 & 0 & 0 & $\begin{array}{ll}12 & 100\end{array}$ \\
\hline
\end{tabular}


Não foi possível realizar a avaliação clínica ou formal da fluência devido a amostra da fala dos participantes ter sido insuficiente para este tipo de análise. O que pudemos observar clinicamente foi que a velocidade de fala de um dos participantes era mais lenta que o esperado, sem que isso prejudicasse a inteligibilidade da fala do mesmo.

No GC dois indivíduos apresentaram disfluências comuns sem contudo serem caracterizadas como risco para o desenvolvimento da gagueira frente a outros aspectos relevantes para tal diagnóstico, acreditamos tratar-se das disfluências comuns do desenvolvimento da fala

- A inteligibilidade da fala

O grau de comprometimento da inteligibilidade da fala dos sujeitos com SK variou de discreto a extremo, sendo este último caracterizado por indivíduos que apresentaram vocalizações indiferenciadas ou ausência de fala. Um dos indivíduos do GI apresentou comprometimento discreto e (1) um comprometimento grave tendo a produção da fala caracterizada basicamente pela produção das vogais, mesmo em repetição de palavras. Outros 4 sujeitos apresentaram comprometimento extremo, tendo um deles a fala caracterizada por vocalizações diferenciadas e produção apenas de vogais e outros três por vocalizações esporádicas indiferenciadas.

A tabela 10 mostra o grau de comprometimento da inteligibilidade da fala dos grupos avaliados. 
Tabela 10. Grau de comprometimento da inteligibilidade de fala dos sujeitos avaliados.

\begin{tabular}{lcccccccccccc}
\hline \multirow{2}{*}{$\begin{array}{l}\text { inteligibilidade } \\
\text { sexo }\end{array}$} & Normal & Discreto & Moderado & Grave & \multicolumn{3}{c}{ Extremo } & \\
\cline { 2 - 14 } & $\mathrm{N}$ & $\%$ & $\mathrm{~N}$ & $\%$ & $\mathrm{~N}$ & $\%$ & $\mathrm{~N}$ & $\%$ & $\mathrm{~N}$ & $\%$ & $\mathrm{~N}$ & $\%$ \\
GI & 0 & 0 & 1 & 16,6 & 0 & 0 & 1 & 16,6 & 4 & 66,6 & 6 & 100 \\
GC & 12 & 100 & 0 & 0 & 0 & 0 & 0 & 0 & 0 & 0 & 12 & 100 \\
\hline
\end{tabular}


Com o objetivo de complementar os achados clínicos sobre a comunicação oral dos indivíduos com SK estudados foram utilizados os subtestes do ITPA. A idéia inicial era a de comparar quantitativamente o desempenho entre indivíduos do GI e do GC porém, dos 6 sujeitos do GI apenas 1 realizou todo o teste e 1 realizou 4 subtestes e 1 apenas 1 subteste. A não realização do teste se deu pela dificuldade dos indivíduos em entender e responder ao mesmo. Cabe ressaltar que os sujeitos do GI que não realizaram os subtestes do ITPA são os que na avaliação clínica apresentaram desempenho com maior comprometimento da linguagem oral.

Os resultados dos sujeitos que realizaram o exame ou parte dele foram apresentados em tabelas que mostram o desempenho baseado no escore bruto e escore escalar em cada subteste.

Os resultados demonstrados nas tabelas referem-se exclusivamente aos indivíduos do GI (N) que realizaram os subtestes do ITPA e aos seus respectivos pares (2N) do GC, portanto, para cada resultado do GI existem 2 resultados na coluna do GC. Não foram expostos os resultados dos sujeitos do GC cujo par do GI não tenha realizado o subteste.

Os valores médios foram achados a partir da soma dos valores individuais e divisão por número de sujeitos que realizaram o teste. Por esta razão, em alguns momentos, os valores podem parecer incoerentes com os resultados brutos obtidos já que para cada faixa etária os escores escalares são diferentes. Consideramos também a possibilidade desse tipo de comparação na medida em que o GC foi elaborado a partir do número, do sexo e idade mental dos sujeitos do GI. O objetivo de propor a média 
para fazer a comparação se deu para que fosse possível a visualização equiparada dos valores e a identificação da discrepância encontrada entre os grupos deste estudo.

O subteste de recepção auditiva evidenciou que o desempenho dos sujeitos com SK é pior que os de seus referentes no GC

Na tabela 11, são mostrados os desempenhos dos sujeitos no subteste de recepção auditiva, relacionando os escores bruto, escalar e idade psicolingüística

Tabela 11. Escore bruto, escalar e Idade psicolinguística no subteste de recepção auditiva dos sujeitos do GI e GC

RECEPÇÃO AUDITIVA

\begin{tabular}{ccccccc}
\hline \multicolumn{2}{c}{ ESCORE BRUTO } & \multicolumn{2}{c}{ ESCORE ESCALAR } & \multicolumn{2}{c}{ IDADE PSICOLINGUÍSTICA } \\
\hline \multicolumn{2}{c}{ GI } & GC & GI & GC & GI & GC \\
(P1) & 3 & 48 & 13 & 42 & $1 \mathrm{a} 11 \mathrm{~m}$ & 11 \\
& & 49 & & 43 & & 11 \\
(P4) & 28 & 48 & 13 & 42 & $5-0$ & 11 \\
& 50 & & 45 & & 11 \\
\hline
\end{tabular}

No subteste de recepção visual, todos os sujeitos do GI que realizaram o exame tiveram o resultado muito inferior aos do GC.

$\mathrm{Na}$ tabela 12, são mostrados os desempenhos dos sujeitos no subteste de recepção visual, relacionando os escores bruto, escalar e idade psicolingüística 
Tabela 12. Escore bruto, escalar e Idade psicolingüística no subteste de recepção visual dos sujeitos do GI e GC

\begin{tabular}{|c|c|c|c|c|c|c|}
\hline \multicolumn{7}{|c|}{ RECEPÇÃO VISUAL } \\
\hline \multicolumn{3}{|c|}{ ESCORE BRUTO } & \multicolumn{2}{|c|}{ ESCORE ESCALAR } & \multicolumn{2}{|c|}{ IDADE PSICOLINGUÍSTICA } \\
\hline \multicolumn{2}{|c|}{ GI } & $\mathrm{GC}$ & GI & $\mathrm{GC}$ & GI & $\mathrm{GC}$ \\
\hline \multirow[t]{2}{*}{ (P1) } & 10 & 32 & 26 & 45 & $4-0$ & 11 \\
\hline & & 31 & & 45 & & 11 \\
\hline \multirow[t]{2}{*}{ (P2) } & 3 & 14 & 26 & 37 & $2-0$ & $5-6$ \\
\hline & & 14 & & 37 & & $5-6$ \\
\hline \multirow[t]{2}{*}{ (P4) } & 3 & 21 & 0 & 37 & $2-0$ & 11 \\
\hline & & 19 & & 36 & & 11 \\
\hline
\end{tabular}

Os valores das médias dos indivíduos no subteste de associação auditiva mostraram que os sujeitos do GI apresentaram valores bem inferiores do que do GC.

$\mathrm{Na}$ tabela 13, são mostrados os desempenhos dos sujeitos no subteste de associação auditiva, relacionando os escores bruto, escalar e idade psicolingüística

Tabela 13. Escore bruto, escalar e Idade psicolingüística no subteste de associação auditiva dos sujeitos do GI e GC 


\begin{tabular}{ccccccc}
\hline \multicolumn{2}{c}{ ESCORE BRUTO } & \multicolumn{2}{c}{ ESCORE ESCALAR } & \multicolumn{2}{c}{ IDADE PSICOLINGUÍSTICA } \\
\hline \multicolumn{2}{c}{ GI } & GC & GI & GC & GI & GC \\
(P4) & 18 & 35 & 0 & 48 & $4-9$ & 11 \\
& 34 & & 47 & & 11 \\
\hline
\end{tabular}

O indivíduo do GI mostrou maior dificuldade no subteste de associação visual que os indivíduos do GC

Na tabela 14, são mostrados os desempenhos dos sujeitos no subteste de associação visual, relacionando os escores bruto, escalar e idade psicolingüística

Tabela 14. Escore bruto, escalar e Idade psicolinguística no subteste de associação visual dos sujeitos do GI e GC

\begin{tabular}{|c|c|c|c|c|c|c|}
\hline \multicolumn{7}{|c|}{ ASSOCIAÇÃO VISUAL } \\
\hline \multicolumn{3}{|c|}{ ESCORE BRUTO } & \multicolumn{2}{|c|}{ ESCORE ESCALAR } & \multicolumn{2}{|c|}{ IDADE PSICOLINGUÍSTICA } \\
\hline $\mathrm{G}$ & & $\mathrm{GC}$ & GI & GC & GI & $\mathrm{GC}$ \\
\hline \multirow[t]{2}{*}{ (P4) } & 3 & 27 & 0 & 39 & $2-6$ & 11 \\
\hline & & 25 & & 37 & & 11 \\
\hline
\end{tabular}

O indivíduo que realizou o teste de expressão verbal apresentou também resultado pior que seus referentes no GC

Na tabela 15, são mostrados os desempenhos dos sujeitos no subteste expressão verbal, relacionando os escores bruto, escalar e idade psicolingüística 
Tabela 15. Escore bruto, escalar e Idade psicolinguística no subteste de expressão verbal dos sujeitos do GI e GC

\section{EXPRESSÃO VERBAL}

\begin{tabular}{|c|c|c|c|c|c|c|}
\hline \multicolumn{3}{|c|}{ ESCORE BRUTO } & \multicolumn{2}{|c|}{ ESCORE ESCALAR } & \multicolumn{2}{|c|}{ IDADE PSICOLINGUÍSTICA } \\
\hline $\mathrm{G}$ & & GC & GI & GC & GI & GC \\
\hline \multirow[t]{2}{*}{ (P4) } & 0 & 29 & 0 & 39 & 1,11 & 11 \\
\hline & & 25 & & 35 & & $9-0$ \\
\hline
\end{tabular}

No subteste de expressão manual o sujeito do GI apresentou resultado pior que os referentes no GC

Na tabela 16, são mostrados os desempenhos dos sujeitos no subteste de expressão manual, relacionando os escores bruto, escalar e idade psicolingüística

Tabela 16. Escore bruto, escalar e Idade psicolinguística no subteste de expressão manual dos sujeitos do GI e GC

\begin{tabular}{|c|c|c|c|c|c|c|}
\hline \multicolumn{7}{|c|}{ EXPRESSÃO MANUAL } \\
\hline \multicolumn{3}{|c|}{ ESCORE BRUTO } & \multicolumn{2}{|c|}{ ESCORE ESCALAR } & \multicolumn{2}{|c|}{ IDADE PSICOLINGUÍSTICA } \\
\hline & & $\mathrm{GC}$ & GI & GC & GI & GC \\
\hline \multirow[t]{2}{*}{ (P4) } & 18 & 27 & 0 & 39 & $4-9$ & 11 \\
\hline & & 25 & & 37 & & 11 \\
\hline
\end{tabular}

No subteste de closura gramatical o resultado do sujeito do GI mostrou-se pior que os do GC. 
Na tabela 17, são mostrados os desempenhos dos sujeitos no subteste de closura gramatical, relacionando os escores bruto, escalar e idade psicolingüística

Tabela 17. Escore bruto, escalar e Idade psicolingüística no subteste de closura gramatical dos sujeitos do GI e GC

CLOSURA GRAMATICAL

\begin{tabular}{|c|c|c|c|c|c|c|}
\hline \multicolumn{3}{|c|}{ ESCORE BRUTO } & \multicolumn{2}{|c|}{ ESCORE ESCALAR } & \multicolumn{2}{|c|}{ IDADE PSICOLINGUÍSTICA } \\
\hline G & & GC & GI & GC & GI & GC \\
\hline \multirow[t]{2}{*}{ (P4) } & 0 & 32 & 0 & 42 & 1,11 & 11 \\
\hline & & 31 & & 41 & & 11 \\
\hline
\end{tabular}

O subteste de closura visual mostrou pior resultado do sujeito do GI que os seus referentes no GC. Nota-se que essa diferença pode ter acontecido, entre outros fatores, pela dificuldade visual que este sujeito apresenta.

Na tabela 18, são mostrados os desempenhos dos sujeitos no subteste de closura visual, relacionando os escores bruto, escalar e idade psicolingüística

Tabela 18. Escore bruto, escalar e Idade psicolingüística no subteste de closura visual dos sujeitos do GI e GC 


\begin{tabular}{ccccccc}
\hline GI & GC & GI & GC & GI & GC \\
$(\mathrm{P} 1)$ & 6 & 35 & 25 & 46 & $2-10$ & 11 \\
& & 36 & & 46 & & 11 \\
$(\mathrm{P} 4)$ & 4 & 34 & 0 & 45 & $2-6$ & 11 \\
& 36 & & 46 & & 11 \\
\hline
\end{tabular}

O sujeito do GI que realizou os testes mostrou desempenho abaixo do GC porém, foi melhor que os outros subteste no geral.

$\mathrm{Na}$ tabela 19, são mostrados os desempenhos dos sujeitos no subteste de memória seqüencial auditiva, relacionando os escores bruto, escalar e idade psicolingüística

Tabela 19. Escore bruto, escalar e Idade psicolingüística no subteste de memória seqüencial auditiva dos sujeitos do GI e GC

\begin{tabular}{|c|c|c|c|c|c|c|}
\hline \multicolumn{7}{|c|}{ MEMÓRIA SEQÜENCIAL AUDITIVA } \\
\hline \multicolumn{3}{|c|}{ ESCORE BRUTO } & \multicolumn{2}{|c|}{ ESCORE ESCALAR } & \multicolumn{2}{|c|}{ IDADE PSICOLINGUÍSTICA } \\
\hline $\mathrm{C}$ & & $\mathrm{GC}$ & GI & $\mathrm{GC}$ & GI & $\mathrm{GC}$ \\
\hline & 34 & 39 & 39 & 43 & 11 & 11 \\
\hline & & 41 & & 44 & & 11 \\
\hline
\end{tabular}

Na tabela 20, são mostrados os desempenhos dos sujeitos no subteste dememória seqüencial visual, relacionando os escores bruto, escalar e idade psicolingüística 
Tabela 20. Escore bruto, escalar e Idade psicolinguística no subteste de memória seqüencial visual dos sujeitos do GI e GC

MEMÓRIA SEQÜENCIAL VISUAL

\begin{tabular}{ccccccc}
\hline \multicolumn{2}{c}{ ESCORE BRUTO } & \multicolumn{2}{l}{ ESCORE ESCALAR } & \multicolumn{2}{l}{ IDADE PSICOLINGUÍSTICA } \\
\hline \multicolumn{2}{c}{ GI } & GC & GI & GC & GI & GC \\
(P4) & 11 & 46 & 27 & 66 & $3-4$ & 11 \\
& 44 & & 46 & & 11 \\
\hline
\end{tabular}

O subteste de closura auditiva também evidenciou pior resultado do indivíduo do GI que os indivíduos do GC.

Na tabela 21, são mostrados os desempenhos dos sujeitos no subteste de closura auditiva, relacionando os escores bruto, escalar e idade psicolingüística.

Tabela 21. Escore bruto, escalar e Idade psicolingüística no subteste de closura auditiva dos sujeitos do GI e GC

CLOSURA AUDITIVA

\begin{tabular}{|c|c|c|c|c|c|c|}
\hline \multicolumn{3}{|c|}{ ESCORE BRUTO } & \multicolumn{2}{|c|}{ ESCORE ESCALAR } & \multicolumn{2}{|c|}{ IDADE PSICOLINGUÍSTICA } \\
\hline$C$ & & $\mathrm{GC}$ & GI & GC & GI & GC \\
\hline \multirow[t]{2}{*}{ (P4) } & 25 & 33 & 23 & 48 & $7-10$ & 11 \\
\hline & & 33 & & 48 & & 11 \\
\hline
\end{tabular}

$\mathrm{Na}$ tabela 22, são mostrados os desempenhos dos sujeitos no subteste de combinação de sons, relacionando os escores bruto, escalar e idade psicolingüística 
Tabela 22. Escore bruto, escalar e Idade psicolinguística no subteste de combinação de sons dos sujeitos do GI e GC

\section{COMBINAÇÃO DE SONS}

\begin{tabular}{|c|c|c|c|c|c|c|}
\hline \multicolumn{3}{|c|}{ ESCORE BRUTO } & \multicolumn{2}{|c|}{ ESCORE ESCALAR } & \multicolumn{2}{|c|}{ IDADE PSICOLINGUÍSTICA } \\
\hline$C$ & & GC & GI & GC & GI & GC \\
\hline \multirow[t]{2}{*}{ (P4) } & 26 & 46 & 32 & 41 & $6-5$ & 11 \\
\hline & & 45 & & 40 & & 11 \\
\hline
\end{tabular}

Para a visualização, comparação e análise dos desempenhos dos sujeitos do GI e do GC, nos 12 subtestes do ITPA, apresentamos os achados segundo a média dos escores brutos, escalares e idade psicolingüística de todos os sujeitos do estudo.

Notou-se que todos os sujeitos do GI apresentaram desempenho bem abaixo dos seus referentes no GC.

A tabela 23 foi elaborada com a reunião de todos os resultados expressos em médias dos escores.

Tabela 23. média dos desempenhos dos sujeitos do estudo nos subtestes do ITPA

\begin{tabular}{lllllll}
\hline Subtestes & ESC. BRUTO & ESC. ESCALAR & ID.PSICOL. \\
& GI & GC & GI & GC & GI & GC
\end{tabular}




\begin{tabular}{lllllll} 
Recepção auditiva & 15,5 & 48,7 & 13 & 43 & 5 & 11 \\
Recepção visual & 5,3 & 21,8 & 17,3 & 39,5 & 2,6 & 9,2 \\
Memória Seqüencial Visual & 11 & 45 & 27 & 56 & 3,4 & 11 \\
Associação auditiva & 18 & 34,5 & 0 & 47,5 & 4,9 & 11 \\
Memória Seqüencial Auditiva & 34 & 40 & 39 & 43,5 & 11 & 11 \\
Associação visual & 3 & 26 & 0 & 38 & 2,6 & 11 \\
Closura visual & 5 & 35 & 12,5 & 45,7 & 2,8 & 11 \\
Expressão verbal & 0 & 27 & 0 & 37 & 1,11 & 10 \\
Closura gramatical & 0 & 31,5 & 0 & 41,5 & 1,11 & 11 \\
Expressão manual & 18 & 26 & 0 & 38 & 4,9 & 11 \\
Closura auditiva & 25 & 33 & 23 & 48 & 7,10 & 11 \\
Combinação sons & 26 & 45,5 & 32 & 40,5 & 6,5 & 11 \\
\hline
\end{tabular}


$\underline{\text { DISCUSSÃO }}$ 


\section{6 - DISCUSSÃO}

\section{- Avaliação Audiológica}

O nosso estudo apontou que $66 \%$ dos indivíduos com SK estudados apresentaram perda auditiva, sendo $75 \%$ com perda auditiva condutiva e $25 \%$ de perdas auditivas mistas. Dois indivíduos da amostra apresentaram audição normal.

Estudos de Toutain et al (1997) apontaram que 39\% dos indivíduos não asiáticos acometidos pela SK tem perdas auditivas. Este estudo referiu-se à perda auditiva condutiva, mas relata que podem ser encontradas também perdas auditivas neurossensorial e mista.

Os achados clínicos de Niikawa et al (1988), relataram a ocorrência de 50\%, dos 62 indivíduos com SK estudados, com perda auditiva, sem contudo especificar o tipo e o grau.

O número de indivíduos com perda auditiva deste estudo é maior que o descrito na literatura porém, a prevalência de perdas condutivas foi ao encontro do que a mesma literatura apontou. Acreditamos que a freqüência maior de perdas auditivas encontradas nos sujeitos deste estudo quando comparados com os dados da literatura seja em decorrência da fissura de palato, comum nesta população, por se tratar de sujeitos registrados em um hospital de reabilitação que atende pessoas fissuradas. Assim aponta Paradise (1976) quando diz que pacientes com fissura palatina apresentam otite média serosa com muita freqüência e de difícil resolução. 
A associação de alterações auditivas e visuais não foi descrita na literatura compilada. Niikawa et. al (1988) mencionaram a ocorrência dos problemas visuais e auditivos sem contudo fazer associação dos mesmos. Uma vez que a presença de alterações visuais e auditivas são previstas isoladamente, a associação delas passa a ser uma possibilidade maior quando se trata de indivíduos fissurados. A presença da fissura torna o sujeito dela acometido mais suscetível a otites que podem causar-lhe a perda auditiva condutiva.

\section{- Avaliação fonoaudiológica clínica}

Os dados encontrados sobre o comprometimento da comunicação oral, na tabela 6, nos permitiram verificar que a totalidade dos sujeitos (100\%) com SK apresentaram algum grau de comprometimento da comunicação oral enquanto $8,55 \%$ dos sujeitos do GC, que representa 5,5\% do total de sujeitos, apresentou comprometimento discreto.

Estes achados mais gerais quanto ao comprometimento da comunicação oral nos remete aos achados fonoaudiológicos de Toutain et al (1997) que apontam os problemas de comunicação como sendo comuns e que o quadro é muito heterogêneo.

Nas publicações existentes sobre indivíduos com SK, não se observou a descrição dos achados fonoaudiológicos de forma mais detalhada ou descritiva, não existe caracterização da comunicação oral desses indivíduos. Nos estudos publicados encontramos informações gerais sobre a comunicação oral dos indivíduos com SK, como Burke et. al (1994), Galan-Gomez et al (1995) e Iliyna et al (1995) que 
mencionam alguns aspectos da comunicação de indivíduos como sendo pobre e de aquisição tardia, mas sem especificar a alteração encontrada.

\section{O uso funcional da comunicação (pragmática) dos indivíduos com SK.}

Ao comparar o desempenho da funcionalidade da comunicação oral do GI com o GC, pudemos verificar todos os sujeitos (100\%) do GI apresentaram comprometimento na área avaliada enquanto no GC $(33,3 \%)$ apresentaram o mesmo tipo de comprometimento.

A dificuldade identificada na manutenção do tema dos indivíduos do GI pode estar relacionada à exigência do desenvolvimento semântico e sintático que, nos indivíduos também se apresenta alterada. A alteração da funcionalidade da comunicação do GI também pode estar relacionada à presença do déficit cognitivo identificado em todos os indivíduos deste grupo.

Vários autores como Vygotsky (1964), Halliday (1975), Mysak (1984), Zorzi (1993) e Lowe (1996) destacam a importância de fatores cognitivo, afetivos e sociais para o desenvolvimento da funcionalidade da comunicação.

Nos participantes do GC, $4(33,3 \%)$ dos 12 sujeitos avaliados apresentaram alterações no aspecto funcional da comunicação oral. A dificuldade foi observada nos 4 sujeitos com idade inferior a 3 anos e, por este motivo, não foram consideradas alterações propriamente ditas. Segundo Perissinoto (1992), a capacidade de relatar fatos 
adequadamente sequencializados faz parte do desenvolvimento da criança a partir dos 4 anos, o que justificaria as dificuldades ainda encontradas nos indivíduos do GC.

\section{- Avaliação da Fala}

A avaliação da Fala permitiu a verificação de aspectos relacionados ao comportamento vocal, a produção dos sons da fala, fluência e inteligibilidade da comunicação oral e se justificou pela presença da fissura de palato na população estudada.

Os achados referente à produção da fala no GI mostrou-se significativamente alterado quando comparado ao GC. Todos os 6 sujeitos do GI (100\%) apresentaram alteração na produção dos sons da fala enquanto 3 sujeitos de 12 avaliados $(24,9 \%)$ do GC as apresentaram.

\section{- Comportamento Vocal}

Três (3) participantes do GI apresentaram leve ou moderada hipernasalidade, sem que isso prejudicasse a inteligibilidade da fala. Um dos participantes também apresentou voz rouca, grave e soprosa e dois também apresentaram voz aguda. Três participantes não puderam ser avaliados neste aspecto por apresentarem reduzida ou ausente produção vocal.

Quanto aos resultados da avaliação vocal, da tabela 8, Burke et al (1994), GalanGomez et al (1995) e Iliyna et al (1995) caracterizam a voz de indivíduos com SK 
estudados como sendo em geral grave, indistinta e hipernasal. Upton et al (2003) identificaram ressonância oral inadequada em 6 indivíduos com SK estudados. Os dois estudos relacionam a presença de alterações no sistema de ressonância à presença de fissura de palato, dado este encontrado também na população do presente estudo.

De acordo com Mattos (1990), Vicente e Buchala (1991), Capelozza Filho e Silva Filho (1994), Chen et al (1994) e Altman (1997), a inadequação velofaríngea pode persistir mesmo após o fechamento do palato e uma das condições determinada por ela é a hipernasalidade, identificada nos 3 sujeitos do estudo em referência.

Quanto ao tipo vocal rouco ou agudo apenas existem relatos da ocorrência sem justificativas para o evento. Neste grupo estudado, o tipo vocal alterado pode ser decorrente de freqüentes processos infecciosos de vias aéreas, dada a deficiência imunológica característica da SK.

Os sujeitos do GC que apresentaram o quadro de disfonia sem contudo apresentar um histórico que o justificasse podem fazer parte do quadro de disfonia apontado por Behlau e Gonçalves (1988), de que 6 a 23,4 \% das crianças fazem parte, ou seja, aqueles em que a criança é acometida da alteração sem justificativa específica.

- Produção dos sons da fala

As informações sobre a produção da fala dos sujeitos com SK foram importantes para melhor caracterizar os aspectos de articulação, voz, fluência e inteligibilidade de fala dos sujeitos deste estudo que, na sua maioria, apresentam fissura de palato. 
Quando comparados os indivíduos do GI com os do GC, verificou-se que o primeiro grupo apresenta $100 \%$ dos indivíduos com comprometimento da produção dos sons enquanto no segundo observou-se 24,9\%. O comprometimento observado nos sujeitos do GC são típicos do desenvolvimento lingüístico de crianças na faixa etária de 2 a 4 anos de idade. Foi esta a idade média dos sujeitos do GC, considerando que a constituição do grupo se deu pela equiparação da idade mental do GI.

Neste estudo identificamos 3 sujeitos do grupo amostral com fissura de palato operados e dois com palato alto, úvula bífida e fissura submucosa, um dos sujeitos com SK não apresentou alteração estrutural de palato.

Dentre as características faciais típicas mais importantes descritas na "pêntade de Niikawa", encontra-se a presença de fissura de palato. O comprometimento da fala, considerando a articulação dos sons, poderiam ocorrer devido à presença desta condição estrutural importante do palato porém, observou-se que o tipo mais freqüente de alteração na produção da fala de indivíduos com fissura de palato, os mecanismos compensatórios, não ocorreram entre os sujeitos deste estudo. Autores como Bzoch (1989), Hall (1991), Rohrich (1996) e Altman (1997) afirmam que o comprometimento na fala do indivíduo com fissura pode ser amenizado se a cirurgia para o fechamento do palato for realizada o mais breve possível, fato este que ocorreu com os sujeitos fissurados deste estudo.

O funcionamento adequado do sistema nervoso central que controla e programa os movimentos da fala, a integridade perceptual auditiva e visual e as condições anatomofisiológicas dos órgãos fono-articulaórios determinam os mecanismos de 
produção da fala (Vicente e Buchala, 1991). O comprometimento da articulação dos sons da fala dos sujeitos deste estudo podem estar relacionada à associação desses fatores já que os mesmos além da fissura apresentam, em casos distintos, deficiência auditiva, visual e mental além da fissura palatal.

O estudo de Upton et al (2003) identificou erros articulatórios, entre outras alterações da comunicação relacionadas à fissura, nos 6 sujeitos com SK fissurados que avaliaram, sem contudo especificar que tipo de erros ocorriam.

- Fluência

A caracterização da fluência da fala se dá a partir da identificação da repetição de sons, sílabas, prolongamentos pausas e bloqueios com tensão. No GI 5 sujeitos não apresentaram amostra de fala suficiente para análise e 1 sujeito apresentou, aparentemente, velocidade de fala mais lenta que o determinado como sendo o normal para adultos, sem que a inteligibilidade da fala pudesse ser comprometida por este fator.

Não foram encontrados estudos na literatura compilada que fizessem qualquer referência à fluência da fala de indivíduos com SK.

- Inteligibilidade da fala

O comprometimento da inteligibilidade da fala do GI apresentou-se em todos os sujeitos $(100 \%)$, já no GC não houve identificação deste tipo de comprometimento. Sobre a inteligibilidade de fala de indivíduos com SK não existem estudos específicos. 
Burke et al (1994), Galan-Gomez et al (1995) e Iliyna et al (1995) descreveram aspectos da comunicação de indivíduos com SK caracterizando a fala dos mesmos como tendo, entre outros comprometimentos, o nível de recepção melhor que o de expressão.

O prejuízo à inteligibilidade da fala dos participantes do GI pode ter sido provocado principalmente pela alteração na produção dos sons da fala em decorrência da associação de fatores como deficiência auditiva, visual, cognitiva e a fissura de palato.

\section{- Avaliação fonoaudiológica complementar}

Os achados sobre a linguagem oral dos sujeitos com SK foram complementados pelo ITPA, nos casos específicos em que os sujeitos realizaram os subtestes. O desempenho dos indivíduos do GI foram dispostos nas tabelas de forma que pudessem ser comparados com o seu referente no GC.

Comparando os dados da avaliação clínica com o Teste Illinois de Habilidades Psicolingüísticas (ITPA), observou-se que o indivíduo com menor alteração da linguagem oral apresentou também menor comprometimento na maioria dos subtestes quando comparado com outros sujeitos do mesmo grupo. As alterações encontradas evidenciaram déficit nas habilidades perceptivas auditivas e visuais, mostrando que as mesmas podem ter influenciado no desenvolvimento das habilidades lingüísticas deste indivíduo. 
Quando comparado com os seus pares do GC observou-se que P4 apresentou desempenho abaixo do esperado, considerando que os sujeitos do GC foram pareados pela idade mental do GI.

$\mathrm{Na}$ literatura compilada não foram encontrados estudos sobre o desempenho de indivíduos com SK no ITPA. 
CONCLUSÕES 


\section{7 - CONCLUSÕES}

Os resultados obtidos nas avaliações clínicas e formais evidenciaram que o quadro de distúrbio de linguagem e fala (forma, conteúdo e uso) estava presente em $100 \%$ da amostra pesquisada. A presença de perda auditiva esteve presente em $66 \%$ da amostra, sendo a maioria do tipo condutiva.

A análise dos resultados obtidos na avaliação fonoaudiológica clínica e complementar sobre a comunicação oral dos indivíduos com Síndrome Kabuki e a comparação desses resultados com o Grupo Controle e a literatura pudemos concluir que:

- Os sujeitos com SK apresentaram relevante comprometimento da funcionalidade da comunicação quando comparados aos indivíduos do GC, sem a referida síndrome. O comprometimento cognitivo pode levar o indivíduo a esta condição e a deficiência auditiva, quando presente, pode agravar o quadro.

- As alterações da fala relacionadas ao tipo vocal e sistema de ressonância podem ser relacionadas principalmente à suscetibilidade a infecções de vias aéreas devido talvez à deficiência imunológica muito comum entre os indivíduos com SK e presente também nesta população estudada, no primeiro caso e, às alterações estruturais do palato também encontradas nos sujeitos com SK deste estudo, no segundo caso;

- As alterações da fala relacionadas à produção dos sons foram encontradas em todos os sujeitos com SK e caracterizadas como relevantes no comprometimento da 
inteligibilidade da fala dos mesmos. Esta alteração também pode estar diretamente relacionada ao déficit cognitivo encontrado nos sujeitos deste estudo e ao comprometimento perceptual auditivo encontrado na população;

- A funcionalidade da comunicação oral também mostrou-se alterada em todos os sujeitos com SK, podendo também estar relacionada ao déficit cognitivo da população estudada;

- O desempenho nos subtestes do ITPA dos indivíduos com SK que os realizaram mostraram-se muito abaixo do que o esperado para a idade dos mesmos evidenciando a presença de alterações perceptuais de ordem auditiva e visual. 


\section{REFERÊNCIAS BIBLIOGRÁFICAS}




\section{8 - REFERÊNCIAS BIBLIOGRÁFICAS}

Altman, EBC Fissuras Lábio Palatinas. 4ª ed. Carapicuíba, São Paulo: Ed. Pró-Fono; 1997

Andrade, CRF Processamento da fala - aspectos da fluência. Pró-Fono; 12(1):69-71, mar; 2000.

Behlau, SM, Gonçalves, MIR Considerações sobre a disfonia infantil. In: Ferreira, LD Trabalhando a voz. 2aed. São Paulo: Summus Editorial; 1988.

Bogossian, MADS. Estudo preliminar sobre a bateria I. T. P. A. Illinois Test of Psicholinguistic Abilities [dissertação de mestrado]. Rio de Janeiro; Pontifícia Universidade Católica do Rio de Janeiro; 1975.

Bogossian, MADS e SANTOS, MJ. Manual do examinador: Teste Illinois de Habilidades Psicolingüisticas. Rio de Janeiro: EMPSI; 1977.

Bogossian, MADS. Uma visão geral do I. T. P. A.: Illinois Test of Psicholinguist Abilities. J. Bras. Reab. Vocal, 1979; 1: 8-10.

Burke, LW. Kabuki Syndrome: Underdiagnosed recognizable pattern in cleft palate patients. Cleft Palate Craniofacial Journal 1994; 32: 77-84. 
Bzoch, KK Comunicative Disorders related to cleft lipand palate, $3^{\mathrm{a}}$ ed. College-Hill Press, Boston, 1989.

Capelozza Filho L e Silva Filho O. G. Fissura Lábio-palatais, In: Petrelli, E. Ortodontia para a Fonoaudiologia, São Paulo: Lovise, 1994. cap.12, p. 195-232,.

Chen, PK, WU, J. T., CHEN, Y. R., NOORDHOFF, M, S. Correction of secondary velopfaryngeal insufficiency in cleft palate patients with the furlon palatoplasty; Plastic and reconstitrutive surgery, 1994. 94(7), p. 933-43, dec,

Conselho Federal de Ffonoaudiologia. Exercício Profissional do Fonoaudiólogo. Brasília, $7^{\circ}$ colegiado 2002.

Chu, DC et al. CNS malformation in a child with Kabuki (Niikawa-Kuroki) syndrome: report and review. American Journal of Medical Genetics 1997; 72(2): 205-9.

- Digilio, MC et al. Congenital herat defects in Kabuki syndrome. American Journal of Medical Genetics 2001; May, 15; 100(4): 269-74 Review 2001.

- Franceschini, P. et al. Lower lip pits and complete idiopathic precocious puberty in a patient UIT Kabuki Make-Up (Niikawa-Kuroki) Syndrome. American Journal of Medical Genetics 1993; 47: 423-5.

Galan-Gomez,, E. et al. Kabuki Make-Up (Niikawa-Kuroki) Syndrome in five spanish children. American Journal of Medical Genetics 1995; 59: 276-282. 
Giachet, CM Displasia fronto-nasal: Comunicação oral em indivíduos com e sem anomalias estruturais do corpo caloso [tese de doutorado]. São Paulo: UNIFESP/EPM; 1996.

Hage, SRV. Avaliando a linguagem na ausência de oralidade: estudos psicolingüísticos. Bauru: EDUSC; 1997.

- Hage, SRV Dispraxia articulatória: correlações com o desenvolvimento da linguagem. In: Marquesan, I.; Zorzi, J. L. (org). Anuário CEFAC de Fonoaudiologia. Rio de Janeiro: Revinter; 1999. p. 119-130.

Hall, CD, Eralding-Kushner, K. J., Argamaso, R. V., Strauch, B. Pharyngeal flap surgery in adults. Cleft Palate craniofacial journal, 28(2), p. 179-82. apr. 1991.

Halliday, M. Learning how to mean: exploration in the development of language. London, Edward Arnold, 1975.

Ilyina, H. et al. Kabuki Make-Up (Niikawa-Kuroki) Syndrome in the byelorussian register of congenital malformations: Ten new observations. American Journal of Medical Genetics 1995; 56: 127-131.

Kirk, SA e Mccarthy, J J The Illinois Test of Psycholinguistic Abilities: an approach to differential diagnosis. Amer. J. Ment. Defic. 1961; 66:399-412. 
Kirk, S. A.; MccarthCARTHY, J. J. \& KIRK, W. D. The Illinois Test of Psycholinguistic Abilities. Urbana: University of Illinois Press: 1968.

Kokitsu-Nakata, N. M. et al. Lower lips pits and anorectal anomalies in Kabuki syndrome. American Journal of Medical Genetics 1999; 86: 282-4.

Kuroki, Y. et al. A new malformation syndrome of long palpebral fissures, large ears, depresses nasal tip and skeletal anomalies associated with postnatal dwarfism and mental retardation The Journal Pediatrics 1981; 99(4): 570-3.

Lerone, M. et al. Ectodermal Abnormalities in Kabuki Syndrome. American Journal of Medical Genetics 1997; 7: 263-6.

Lower, RJ Fonologia: avaliação e intervenção: aplicações na patologia da fala. Porto Alegre: Artes Médicas, 1996.

Lynch, SA et al. Kabuki syndrome-like features in monozygotic twin boys with a pseudodicentric chromosor 13. Medical Genetics1995; 32: 227-230.

Makita, Y. et al. Kabuki make-up syndrome is not caused by microdeletion to van der Woude syndrome critical region at 1q32-q41. Medical Genetics 1999; 86: 285-8.

Matsune, K. et al. Craniofacial and dental characteristics of Kabuki syndrome. American Journal of Medical Genetics 2001; Jan, 15; 98: 185-90. 
Mattos, ALG Padrões de articulações compensatórias de indivíduos com inadequação velofaríngea: revisão de literatura, monografía de especialização, Rio de Janeiro, 1990.

Mhanni, AA et al. Kabuki syndrome: description of dental findings in 8 patients. Clinical Genetics 1999; 56: 154-7.

Mysak, ED Patologia do sistema da fala. Rio de Janeiro: Atheneu, 1984.

Niikawa, N. et al. Kabuki make-up syndrome: A syndrome of mental retardation, unusual facies, large and protruding ears, and postnatal growth deficiency The Journal of Pediatrics 1981; 99: 565-9.

Niikawa, N. et al Kabuki Make-Up (Niikawa-Kuroki) Syndrome: a study of 62 patients. American Journal of Medical Genetics 1988; 31: 565-89.

Northern, J. e DOWNS, MP Audição em Crianças. São Paulo: Manole LTDA, 1989.

Osgood, CE A behaviorist analysis of perception and language as cognitive phenomena: contemporary approaches to cognition. Cambridge: Harvard University Press; 1957. p. 75-118.

Paradise, JL. Management of middle ear efusions in infants with cleft palate - Ann. Otol. rhinol. laryngol., 85 (2 Supp125 Pt 2): 285 - 8, 1976.

Perissinoto, J. Avaliação básica da linguagem infantil. São Paulo, 1992. 
Pinheiro, AMV Leitura e Escrita: uma abordagem cognitiva. Campinas: Editorial Psy 2, 1994.

Rohrich, RJ, Rowsell, AR, Johns, DF, Drury. MA, Watson D. J. Timing of hard palatal closure: a critical long-term analisys, Plastic and Reconstructive surgery, 1996. 98(2), p. 236-46, aug,

Santos, MJ Adaptação e avaliação de três subtestes do Illinois Test of Psicholinguistic Abilities [dissertação de mestrado]. Rio de Janeiro; pontifícia Universidade Católica do Rio de Janeiro; 1977.

Santos, MTM. e PEREIRA, L. D. Consciência fonológica. In: Pereira, L. D. \& Schochat, E. (Eds.). Processamento auditivo central: Manual de avaliação. São Paulo: Lovise; 1997. p. (?)

Toutain, A. et al. Deafness and Mondini dysplasia in Kabuki (Niikawa-Kuroki) syndrome. Report of a case and review of the literature. Genetic Counseling 1997; 8(2): 99-105.

Vicente, MCZ, Buchala, RG Atualização da terminologia dos distúrbios articulatórios encontrados em falantes do português com fissura de lábio e palato, Distúrbios da Comunicação, 19914(2), p. 147-152, out.,.

Vygotsky, L. Thought and language. Cambridge, Mass: MIT Press, 1964. 
Yavas, M.; Hernandorena, C. e Lamrecht, R. Avaliação fonológica da criança: reeducação e terapia. Porto Alegre: Artes Médicas; 1991.

Zorzi, J. L. Linguagem e desenvolvimento cognitivo. São Paulo: Pancast, 1993. 
ANEXOS 


\section{Anexo I}

\section{TERMO DE CONSENTIMENTO LIVRE E ESCLARECIDO}

$\mathrm{Eu}$,

portador de $\mathrm{RG} \mathrm{N}^{\mathrm{o}}$

residente à Rua (Av.) , $\mathrm{N}^{\mathrm{o}}$ , na cidade de Estado

(responsável pelo(a) menor matriculado no HRAC com o $\mathrm{N}^{\circ}$ concordo em participar na (autorizo sua participação na)* pesquisa de Título: "Síndrome Kabuki: Diagnóstico Fonoaudiológico", realizada por: Aline Silva Lara de Alvarenga; No do Conselho: CRFa.07246, sob orientação do Dr. Neivo Luiz Zorzetto; $\mathrm{N}^{\circ}$ do Conselho:

A referida pesquisa tem como objetivo realizar o diagnóstico fonoaudiológico em indivíduos portadores da Síndrome Kabuki.

Fui orientado:

- que serei submetido à avaliação fonoaudiológica de acordo com a idade e escolaridade (anamnese, avaliação clínica, avaliação audiológica, avaliação vocal, I.T.P.A - Teste Illinois de Habilidades Psicolingüísticas, P.C.F. - Prova de Consciência Fonológica e T.D.E. - Teste de Desenvolvimento Escolar);

- que precisarei comparecer ao HRAC por pelo menos dois dias consecutivos, com recursos financeiros próprios;

- que para análise dos resultados, as etapas 3 e 4 da avaliação (avaliação clínica e formal) serão gravadas em vídeo e a avaliação vocal gravada em MD para análise acústica;

- que este estudo poderá trazer benefícios para as pessoas com a Síndrome Kabuki na medida em que os profissionais que trabalham com pessoas com essa síndrome adquirirem mais conhecimento sobre a mesma;

- que serei encaminhado para intervenção fonoaudiológica, se necessário.

Estou ciente também de que minha(sua) participação é voluntária e dela posso desistir a qualquer momento, sem explicar os motivos e sem comprometer meu tratamento no HRAC.

Bauru,

Assinatura do Paciente (Responsável)*

* Em caso de menor de idade $(<21$ anos) ou incapaz.

Nome do Pesquisador Responsável: Aline Silva Lara de Alvarenga

Endereço Institucional: Rua Silvio Marchione, 3-20 - Bauru/SP - 17.043-900.

Telefone: (14) 3235-8434 (Secretaria de Pós-Graduação) 